\title{
Trauma en el sistema nervioso central y su reparación
}

\author{
M. Nieto-Sampedro a , J.E. Collazos-Castro ${ }^{\text {a }}$, J.S. Taylor ${ }^{a}$, G. Gudiño-Cabrera ${ }^{\text {b }}$, \\ E. Verdú-Navarro ${ }^{c}$, J.I. Pascual-Piédrola ${ }^{d}$, R. Insausti-Serrano ${ }^{e}$
}

\author{
TRAUMATIC INJURIES TO THE CENTRAL NERVOUS SYSTEM AND THEIR REPAIR
}

\begin{abstract}
Summary. Development. Brain and spinal cord lesions have an increasing social and economic importance. Accidental trauma of various kinds is the main cause of mortality of children and young adults in developed countries. Only cardiac disease and cancer surpass the number of death caused by accidents and, examining the number of potential work-years lost, CNS lesions surpass all other problems. Most brain and spinal cord injuries cause chronic incapacity and frequentlyoccur to individuals under 45 years of age. Edema and other acute events can be efficiently treated and CNS lesions may not be mortal, but are incurable. Conclusion. The final outcome of CNS injury depend on the area damaged and the extent of the lesion, but the best present therapies can offer is relief of the symptoms and rehabilitation. This review examines the present state of functional repair of experimental central nervous system trauma. [REV NEUROL 2002; 35: 534-52]

Key words. Brain. Function recovery. Injury. Lesion repair. Locomotion. Neuronal death. Sensorimotor recovery. Spinal cord. Trauma. Visceral function. Voluntary movement.
\end{abstract}

\section{RESPUESTA NEURAL A LOS TRAUMAS CEREBRAL Y MEDULAR}

Las lesiones del cerebro y médula espinal están adquiriendo una importancia social y económica creciente en los países desarrollados. Los accidentes de todo tipo son la causa principal de la muerte de niños y adultos jóvenes, sólo superada como agente causal para todas las edades por las enfermedades cardíacas y el cáncer. Considerando el problema como número de años de vida (y trabajo) potenciales perdidos, las lesiones superan a todos los restantes problemas, porque ocurren sobre todo a personas de edad inferior a los 45 años. En España sufren lesiones medulares, en su mayoría traumáticas (81\%), 10 de cada millón de habitantes. En el pasado las lesiones medulares graves solían ser mortales a corto plazo. Actualmente los tratamientos han avanzado lo suficiente para poder salvar la vida a muchas de las víctimas, aunque todavía no para curarlas. Las terapias actuales tratan el edema agudo y alivian los síntomas, pero hasta el momento no se ha descrito ningún tratamiento integral que restituya las funciones sensitivomotoras y viscerales perdidas de manera reproducible y suficientemente fiable. Tras la estabilización vital, avances en la rehabilitación enseñan a los pacientes a adaptarse y a vivir lo mejor posible con las consecuencias de la lesión; consecuencias que, como es lógico, dependen finalmente del área del SNC dañada y de la gravedad de la lesión.

La intratabilidad de las lesiones del cerebro y de la médula espinal era prácticamente un dogma hasta hace tan sólo dos décadas. Desde entonces, la neurociencia ha realizado avances es-

Recibido: 26.08.02. Aceptadotras revisión externa sinmodificaciones: 28.08.02. ${ }^{a}$ Grupo de Plasticidad Neural. Instituto Cajal de Neurobiología. CSIC. Madrid. Unidad de Neurología Experimental, Hospital Nacional de Parapléjicos. Toledo. ${ }^{b}$ Departamento de Biología Celular y Molecular. Universidad de Guadalajara. Jalisco, México. ${ }^{C}$ Grup de Neuroplasticitat i Regeneració. Universitat Autònoma de Barcelona. Bellaterra, Barcelona. ${ }^{d}$ Unidad de Regeneración Neural. Servicio de Urología. Servicio Navarro de Salud. Pamplona. ${ }^{e}$ Departamento de Salud. Facultad de Medicina. Universidad de Castilla-La Mancha. Albacete, España.

Correspondencia: Dr. Manuel Nieto Sampedro. Instituto Cajal de Neurobiología. CSIC. Av. Dr. Arce, 37. E-28002 Madrid. Fax: +34 915 854.754. E-mail. mns@cajal.csic.es

Agradecemos muy sinceramente las críticas, comentarios y contribución desinteresada del Dr. Óscar Herreras. El trabajo de nuestro equipo ha sido financiado por el CSIC, el FIS, la CICYT y la Unión Europea.

(C) 2002, REVISTA DE NEUROLOGÍA peranzadores, primero reconociendo que tanto la función como la estructura del SNC son altamente adaptables, plásticas; después, comenzando a desvelar las bases celulares y moleculares de esa plasticidad. El razonamiento subyacente es que, si conocemos las posibilidades de respuesta natural del SNC a las perturbaciones externas (una de ellas, las lesiones), podremos utilizar esta información para la reparación del tejido lesionado. Estos estudios ya han permitido la reparación parcial de lesiones experimentales y nos permiten encarar el futuro con mayor optimismo. Comenzamos a saber, a grandes rasgos, cuáles son los problemas fundamentales que plantean las lesiones y qué tratamientos son teóricamente necesarios. Queda el trabajo de hacerlo y, dada la complejidad del problema, este trabajo puede ser largo y arduo.

Los traumas graves del SNC desencadenan cascadas de acontecimientos perjudiciales que desearíamos detener, y beneficiosos que quisiéramos potenciar [1]. Después de una lesión la barrera hematoencefálica y los vasos sanguíneos locales quedan destruidos lo que, unido al espasmo vascular, causa isquemia y sus asociados, anoxia e hipoglucemia. Células de la sangre y proteínas del suero invaden el área lesionada. El edema, derivado tanto de la acumulación de fluido extracelular como de la inflamación de los astrocitos, es obvio 24 horas después de la lesión. Tras una contusión, pueden observarse inmediatamente anomalías estructurales y electrofisiológicas en los axones, tanto de la sustancia gris como de la blanca [2]. La necrosis y degeneración de la mielina de estos axones se dan 8-24 horas más tarde y la acumulación de fagocitos sanguíneos, que eliminan la mielina degenerada y otros residuos celulares, ocurre unas 48 horas después.

El proceso degenerativo, sin embargo, ni se termina inmediatamente después de la lesión, ni se restringe al sitio primariamente lesionado. Un fenómeno destructivo más insidioso extiende la muerte neuronal en el tiempo y en el espacio. La llamada muerte neuronal secundaria o tardía comienza uno o dos días tras la lesión y es responsable de la muerte de más neuronas que el daño neuronal atribuible directamente a la lesión o muerte primaria. El tejido neural cercano al área lesionada o conectado con ella presenta actividades eléctrica y funcional deprimidas, y se verá afectado por la muerte neuronal secundaria. Esta zona, llamada 'zona de penumbra' en las lesiones isquémicas, evoluciona hacia lesión secundaria y es posiblemente responsable de la pérdida de la función en la mayoría de los traumas de cerebro y médula espinal. 
El trauma causa muerte de neuronas y células gliales, destrucción de vasos sanguíneos y lesión de tractos axonales. Como las neuronas muertas no son reemplazadas y los axones lesionados no regeneran espontáneamente, los trastornos funcionales son permanentes. Las aproximaciones experimentales para intentar mantener o recuperar funciones se han dirigido a: 1 . Prevenir o disminuir la muerte neuronal secundaria; 2. Regenerar los axones lesionados, y 3. Restituir las neuronas perdidas. En los últimos años se han realizado avances significativos en estos temas y, en algunas publicaciones, se informan mejoras en la función. Sin embargo, hasta la fecha, tanto la reparación anatómica como la mejora funcional obtenidas son pequeñas y las estrategias utilizadas se enfrentan a dificultades adicionales en su aplicación a pacientes. La evaluación de las funciones sensorial y motora ha sido un tópico particularmente confuso en los modelos de lesión experimental. Frecuentemente, los modelos de lesión utilizados no guardan relación con la patología humana y no está claro si las ganancias funcionales obtenidas en animales son extrapolables a las lesiones en humanos.

\section{REPARACIÓN FUNCIONAL ¿QUÉ SE HA LOGRADO HASTA AHORA?}

El compendio clásico de Cajal Estudios sobre la degeneración y regeneración del sistema nervioso (1914) [3], incluye estudios iniciales sobre reparación de lesiones en el sistema nervioso central, publicados por Francisco Tello en 1911 [4]. Tello trasplantó fragmentos de nervio ciático en diversos sitios del sistema nervioso central, y observó que las células de Schwann estimulaban el crecimiento de las fibras nerviosas centrales. Desgraciadamente, estos estudios fueron interrumpidos por la muerte de Cajal, la guerra civil española y el posicionamiento religioso-político de Tello. Fueron reanudados más recientemente por otros investigadores, con resultados llamativos, aunque incompletos. A principios de los años ochenta, Aguayo y David [5], en Montreal (Canadá), demostraron que el trasplante de un segmento de nervio periférico mielinizado (ciático) en sitios lesionados del sistema nervioso central permitía a los brotes axonales crecer largas distancias, imposibles en ausencia del trasplante. El problema del crecimiento axonal parecía resuelto, pero la restauración funcional depende de la formación de sinapsis con la diana adecuada y esto no ocurría. Cuando las fibras centrales salían del nervio periférico eran incapaces de crecer más de algunas micras, formando contactos escasos e improductivos. Por esa misma época, Nieto-Sampedro probó que las lesiones inducían un aumento muy significativo en la producción de factores neurotróficos por el tejido lesionado [6]. Estos factores permitían la supervivencia de neuronas trasplantadas y su integración sináptica parcial con el tejido huésped. Además de explicar en parte la plasticidad sináptica, ésta era una inesperada respuesta de autorreparación del tejido nervioso central. Aunque ninguno de los dos trabajos conseguía la reparación de lesiones del cerebro o de la médula espinal, posiblemente ambos contribuyeron a cambiar la actitud pesimista de los investigadores. Desde entonces, la reparación de esas lesiones tenía una cierta base racional y parecía más posible.

A finales de la década de los ochenta Caroni y Schwab iniciaron un abordaje complementario. Estos investigadores encontraron que la mielina central expresa componentes capaces de inhibir el crecimiento axonal [7]. Anticuerpos contra esos componentes eran capaces de inducir la regeneración de algunos axones del haz corticospinal (aproximadamente el 5\%) en la médula espinal lesionada. Las fibras no cruzaban la zona dañada, más bien rodeaban la lesión, creciendo a través del tejido no lesionado [8]. El anticuerpo antimie- lina, además de promover regeneración axonal, induce la formación de brotes colaterales en las fibras no lesionadas. Bajo ciertas circunstancias, este tipo de plasticidad podría ayudar a la recuperación funcional, aunque la evidencia experimental es escasa. La mielina del SNChumano también expresa proteínas inhibidoras del crecimiento axonal cuya actividad también neutraliza el anticuerpo. El tratamiento con anticuerpos contra los inhibidores del crecimiento axonal presentes en la mielina puede tener potencial clínico, particularmente en lesiones incompletas, y podría aplicarse sinergísticamente con otras terapias, aunque muchos problemas básicos continúan sin resolverse. Al mismo tiempo, otros investigadores, particularmente los grupos de Silver en EE.UU. y de Nieto-Sampedro en Madrid, hacían énfasis en los proteoglicanos de la superficie de los astrocitos reactivos como los inhibidores más generales del crecimiento axonal a los que había que neutralizar $[9,10]$.

El siguiente avance significativo vuelve a la estrategia de Tello, con el trasplante en ratas con sección medular completa de nervios intercostales, junto con el factor neurotrófico FGF-1, en fibrina. El equipo que realizó este trabajo (Cheng y Olson, en Stocolmo, Suecia) consiguió, por vez primera, mostrar recuperación parcial de la función de los miembros posteriores en correlación con la restitución anatómica de haces nerviosos que comunican cerebro y médula, entre ellos el haz corticospinal [11]. En los últimos años se han realizado injertos de nervio periférico en la médula lesionada de unos pocos pacientes, sin obtener una repercusión funcional significativa. Sin embargo, no puede descartarse todavía la utilidad de esta técnica en combinación con otro tipo de intervenciones.

Podemos ubicar también dentro de esta estrategia el trasplante en lesiones de células de glía envolvente de bulbo olfatorio. Las propiedades especiales de esta glía, intermedias entre las de los astrocitos y las células de Schwann, habían sido descritas por Doucette en Canadá. Nieto-Sampedro y Ramón-Cueto en Madrid desarrollaron el cultivo y la purificación de la glía envolvente a partir de bulbo olfatorio de rata adulta. La glía purificada fue trasplantada en la médula espinal de ratas adultas que habían recibido una transección en la rama central de la raíz dorsal T8. Sin ayuda, las fibras seccionadas nunca volvían a penetrar en la médula espinal. Con ayuda de trasplantes de glía envolvente, haces de aferentes sensoriales penetraban en la médula, cruzando la mielina de la banda de Lissauer y, algunos, alcanzando el asta dorsal contralateral [12]. Este grupo ha continuado, a partir de 1994, el trabajo de regeneración de raíces sensoriales, trabajo que ha ayudado a definir el análisis de la reparación de lesiones medulares.

La publicación de estos resultados ha iniciado una carrera de aplicaciones de los trasplantes de glía envolvente a lesiones medulares, incluidos los estudios de remielinización de Imaizumi et al [13], de reparación del haz corticospinal de Raisman et al [14] y reparación de transecciones medulares completas, de Ramón-Cueto et al [15]. Raisman utilizó en su estudio lesiones electrolíticas selectivas del tracto corticospinal, en condiciones óptimas para la regeneración: la lesión abarca sólo 500 micras y no produce hemorragia, ni entrada de fibroblastos en la médula. Las células trasplantadas llenaban la lesión, uniendo sus bordes proximal y distal, y entrando en contacto directo con los axones. A pesar de ello, el número de axones regenerados fue pequeño y el trabajo ha sido criticado por la posibilidad de que las lesiones fueran incompletas.

En cuanto a los resultados recientes de Ramón-Cueto et al [15], diversos grupos hemos intentado reproducirlos, hasta ahora con poco éxito. En todo caso, estos resultados han creado grandes expectativas de tratamiento de lesiones medulares, mezcladas con interrogantes sobre lo que se puede esperar y cuándo. Actual- 
mente, nuestros grupos están evaluando terapias potenciales tanto en lesiones específicas como en modelos de contusión medular, correlacionando la recuperación funcional y electrofisiológica con análisis comportamental cinético y cinemático, mediciones no realizadas en los estudios precedentes.

A lo largo de los años se han evaluado muchas estrategias en búsqueda de regeneración axonal. Entre éstas se encuentran los trasplantes de astrocitos inmaduros y microglía y los trasplantes de otros tipos de células, entre ellas fibroblastos meníngeos, macrófagos, fragmentos de tejido neural embrionario, células madre y factores tróficos purificados o a través de trasplantes de células transfectadas para que los produzcan, el implante de moléculas de la matriz extracelular como el colágeno o la laminina, la administración de anticuerpos que neutralizan moléculas inhibitorias del crecimiento, etc. Los resultados de estos trabajos se discuten en esta revisión, intentando concretar y precisar las lesiones del sistema nervioso que se pueden reparar, las estrategias que se pueden combinar y los resultados que es realista esperar.

\section{LOS PROBLEMAS \\ La muerte neuronal retrasada o secundaria}

Desde el punto de vista biológico, la falta de recuperación funcional del SNC lesionado no es un problema ni de falta de iniciación de brotes axonales, ni de incapacidad de su elongación a distancias largas. Más bien está relacionado con la llamada muerte neuronal secundaria o retrasada y con la formación en la zona de lesión de un ambiente inhibitorio del crecimiento axonal. Los patrones de muerte neuronal dependen del tipo de agresión y de si ésta es restringida o generalizada. El riesgo celular básico tras una lesión traumática, durante trombos, aneurismas, paro cardiorrespiratorio, choque hipoglucémico, etc., es la falta de oxígeno o de sustratos oxidables. Las agresiones restringidas causan la muerte rápidamente (1-6 horas poslesión) a las neuronas en la zona directamente afectada por la lesión y en la zona circundante o zona de 'penumbra'. En cambio, en los accidentes generalizados la duración del episodio es crítica y la muerte neuronal ocurre con un retraso de hasta varios días (muerte retrasada o secundaria). Las diferencias en el patrón de muerte son claras e indican que están causadas por mecanismos distintos, que aún no conocemos. Sabemos que las células mueren porque desaparecen, pero el momento preciso del deceso y su descripción apenas se han investigado.

En el grupo de episodios focales, el núcleo de la lesión, sea de origen traumático o isquémico, presenta una situación incompatible con la supervivencia celular. La lesión va acompañada de infiltración leucocitaria en el SNC y liberación de: citocinas proinflamatorias, radicales libres de oxígeno y nitrógeno, metabolitos del ácido araquidónico, aminoácidos excitatorios, ácido quinolínico y proteasas. La acidez del espacio intercelular se eleva, el ion potasio $\left(\mathrm{K}^{+}\right)$se acumula y el calcio intracelular aumenta hasta niveles tóxicos. Durante mucho tiempo se pensó que la difusión de estos agentes a la región circundante, junto con la hipoperfusión y el metabolismo comprometido, eran suficiente para explicar la extensión de la muerte neuronal a la zona de penumbra, que alcanza en unas pocas horas un volumen varias veces mayor que el núcleo inicialmente afectado. La alteración homeostática es tal que la muerte celular parece inevitable y sobrevendría también por cada una de las distintas razones paralelas que concurren independientemente. Cabe preguntarse entonces: si las variables alteradas son conocidas, ¿por qué no se ha conseguido controlar o paliar el daño neuronal con estrategias clínicas adecuadas? ¿Es realmente un proceso irreversible tras sus primeros estadios? El escaso éxito tanto clínico como experimental es, creemos nosotros, debido al tratamiento parcial o excesivamente desglosado del problema. La mayoría de los modelos experimentales están dirigidos a examinar la incidencia específica e independiente que cada uno de los múltiples agentes y factores neurotóxicos tiene sobre la supervivencia, prestando escasa o nula atención a la evolución del estado funcional de las células [16]. La actuación de bloqueadores de canales de $\mathrm{Ca}^{++}$, de receptores de Glu, tamponadores de $\mathrm{pH}$ o reductores de radicales libres, tiene éxito donde debe tenerlo: en los modelos experimentales diseñados ad hoc para confirmar su acción neurotóxica, de todos conocida. Pero su eficacia en modelos reales es limitada, a pesar de la confusión causada por el permanente goteo de éxitos aparentes por tratamientos parciales, convenientemente refutados por otros tantos fracasos. El problema clínico no será resuelto buscando variantes metodológicas que favorezcan la neurotoxicidad de moda (y por lo tanto controlable en el laboratorio) de uno u otro factor. El problema necesita ser tratado de forma global, teniendo en cuenta que cada uno de los posibles procesos afectados forma parte, en el tejido sano, de un entramado metabólico, funcional y celular complejo, cuya característica más destacable es precisamente su estabilidad global. Alteraciones moderadas y transitorias de un factor potencialmente neurotóxico ocasionan siempre modificaciones, también transitorias, en muchos otros que también son neurotóxicos (y en otros que no lo son). Los procesos neurodegenerativos están contrarrestados por la liberación de factores neuroprotectores, antinflamatorios, antioxidantes, neurotróficos y neuritogénicos.

En definitiva, la región de penumbra es una zona de coexistencia, en equilibrio dinámico, de factores favorecedores e inhibidores de la supervivencia neuronal y de la degeneración y regeneración axonal. La estrategia básica para favorecer la reparación funcional del SNC es la modulación o modificación de este equilibrio. La importancia de controlar la muerte neuronal retrasada o secundaria no necesita ser exagerada. Los déficit funcionales más graves tras lesiones del SNC podrían probablemente limitarse en muchos casos si pudiéramos controlar esta muerte neuronal. Además, los procesos moleculares implicados parecen afines a los que conducen a la pérdida progresiva de neuronas en las enfermedades neurodegenerativas. Estas enfermedades (Alzheimer, Parkinson y Huntington) constituyen posiblemente uno de los mayores retos clinicosociales y económicos del nuevo siglo.

\section{Astrocitos reactivos y cicatriz glial}

La muerte neuronal secundaria y los componentes celulares y moleculares que la causan contribuyen además a generar en la zona lesionada un ambiente hostil al crecimiento axonal. Los principales responsables son las células y moléculas de la llamada 'cicatriz glial', formada principalmente por astrocitos y microglía reactivos, fibroblastos y matriz extracelular. Los astrocitos, componentes mayoritarios de la cicatriz glial, son posiblemente las células más plásticas del SNC, capaces de cambiar de número y morfología en respuesta a perturbaciones. Tras una lesión se tornan 'reactivos' o 'fibrosos', palabras cuyo significado referido a astrocitos dista de ser preciso. La mayor parte de los investigadores sobrentiende que esos nombres indican células de mayor tamaño que los astrocitos normales o 'en reposo'. Los astrocitos reactivos muestran un gran incremento en la expresión de filamentos intermedios, lo que les confiere el aspecto 'fibroso' que les da su nombre alternativo. Los filamentos intermedios son reconocidos por anticuerpos contra la proteína fibrilar ácida de la glía (GFAP), el marcador más típico de los astrocitos reactivos. La 'cicatriz glial' consiste esencialmente en una acumulación de 
astrocitos fibrosos hipertróficos en la superficie de la lesión. Fibroblastos del tejido conjuntivo adyacente proliferan sobre la capa de astrocitos fibrosos, depositan colágeno y completan la formación de una nueva frontera con el resto del organismo. Esta frontera suele separar neuronas que antes de la lesión estaban conectadas y es un serio obstáculo para el restablecimiento de nuevas conexiones. Las neuronas que han perdido su inervación original son inervadas por neuronas cercanas no dañadas, fenómeno que, en general, no conduce a la recuperación de la función primitiva. La formación de astroglía reactiva es inducida por cualquier daño al SNC y representa el intento del SNC de aislarse de las influencias incontroladas del resto del organismo, reconstituyendo una nueva glia limitans. Esta nueva glia limitans o 'cicatriz glial' es también, sin embargo, el mayor obstáculo para la restitución de las conexiones dañadas. Así, desde el punto de vista clínico, los astrocitos muestran simultáneamente aspectos beneficiosos y deletéreos. Estos papeles aparentemente conflictivos son producto de la contradicción entre imperativos inmediatos de supervivencia y la necesidad de restituir las funciones perdidas. Desdeel puntode vista de la restitución de funciones, lainhibición completa de la cicatriz glial parecería razonable. Pero esta inhibición posiblemente comprometería la supervivencia del organismo. La situación óptima sería, tal vez, la inhibición controlada de la formación de cicatriz glial durante ventanas temporales que permitiesen la restitución de conexiones funcionales.

¿Proliferan los astrocitos en un mamífero adulto? El número de astrocitos permanece estacionario en el adulto, pero son capaces de dividirse en respuesta al daño o muerte neuronal y una fracción de los astrocitos en la 'cicatriz glial' es el resultado de la proliferación. Está modulada por dos tipos de molécula: los mitógenos, cuya presencia en el cerebro es bien conocida, y los inhibidores de la proliferación, antimitóticos, descritos más recientemente [17]. La entrada de los astroblastos en el ciclo celular y su proliferación están mediadas por la unión del factor de crecimiento epidérmico (EGF), a su receptor (EGFR), una tirosincinasa de membrana bien caracterizada y clonada. Aunque el sistema bioquímico parece bien conocido, bastantes aspectos de su función fisiológica aún permanecen oscuros. Uno de ellos es un inhibidor de la división presente en la fracción soluble de extractos de cerebro, capaz de detener la proliferación y, probablemente, de modular la formación de astrocitos reactivos. Anticuerpos contra EGFR, que secuestran el inhibidor, inducen astrogliosis. La prueba complementaria sería demostrar que el inhibidor puede disminuir la astrogliosis inducida por una lesión.

El inhibidor ha sido purificado a homogeneidad y caracterizado fisicoquímicamente por el grupo de Plasticidad Neural del Instituto Cajal, que ha estudiado también su localización celular y subcelular y su biosíntesis [18,19]. Ha sido llamado neurostatina y es un gangliósido complejo, O-acetilado en un ácido neuramínico. El estudio de sus propiedades biológicas y la exploración de su potencial en biomedicina están en curso y requerirá varios años. La neurostatina puede controlar también la proliferación de astrocitomas, el tipo de tumor maligno más frecuente en el cerebro y la médula espinal.

Los astrocitos que proliferan en el SNC de mamíferos adultos pueden originarse: a) por desdiferenciación de astrocitos maduros a astroblastos; b) a partir de precursores de astrocitos, conservados en el adulto; c) a partir de nuevos astroblastos, derivados de células madre, y d) de todas estas posibilidades. La regulación de la contribución de cada una de esas fuentes de nuevos astrocitos y el papel de la neurostatina en la generación de astroblastos necesitan investigación adicional. La reacción glial inflamatoria, con infiltración leucocitaria y producción de citotoxinas, pero también de factores antinflamatorios, antioxidantes, neurotróficos y neuritogénicos, en suma, la coexistencia de factores favorecedores e inhibidores, tanto de la muerte neuronal como de la regeneración axonal [20, 21], definen una situación de equilibrio inestable en cuya modulación la neurostatina podría tener un papel importante.

\section{La superficie del astrocito: promotora e inhibidora de la regeneración axonal}

Los astrocitos presentan una dualidad de propiedades benéficodeletéreas especialmente notorias cuando consideramos la restitución de funciones biológicas tras una lesión. El tipo de agresión a que es sometido el SNC determina la composición celular de la 'cicatriz glial'. Sus componentes astrocitarios mayoritarios son de dos tipos: astrocitos fibrosos hipertróficos y astroblastos. El origen y las propiedades de interacción con neuritas de ambos tipos celulares son también diferentes, incluso opuestos. Los astrocitos fibrosos hipertróficos en la 'cicatriz glial' son un obstáculo inhibitorio para la regeneración de axones lesionados, mientras que los astroblastos son un sustrato excelente para el crecimiento de axones y dendritas (neuritas). Los cambios inducidos por las lesiones en las moléculas de la superficie de estos tipos astrocitarios son muy distintos: los astroblastos expresan proteoglicanos promotores del crecimiento; los astrocitos fibrosos hipertróficos expresan otros proteoglicanos inhibidores de la iniciación, adhesión, crecimiento y orientación de las neuritas [22-24].

No es posible cultivar astrocitos reactivos fibrosos. Los astrocitos que crecen en cultivo son células epitelioides poligonales, más parecidas a astroblastos que a astrocitos maduros. Cuando estas células son tratadas con dibutiril-AMP-cíclico (diBcAMP), su morfología cambia, transformándose en células estrelladas con niveles elevados de filamentos de GFAP. Ello indujo a proponer a las células tratadas con diBcAMP como modelos in vitro de astrocitos reactivos. Desgraciadamente, la superficie de estas células posee más bien las propiedades de los astroblastos que las de los astrocitos reactivos [25]. La gliosis provocada por lesiones ha tenido que ser modelada de manera más indirecta.

Las lesiones abiertas evocan un tipo de gliosis, llamada anisomórfica, diferente de la gliosis inducida por lesiones sin ruptura directa de la glia limitans, ni contacto directo sangre-SNC, denominada isomórfica. Por ejemplo, la ablación de la corteza entorrinal provoca gliosis anisomórfica en esta corteza, alrededor de la lesión; y gliosis isomórfica en el hipocampo desaferentado. La gliosis isomórfica se puede inducir también en el hipocampo por inyección intraventricular de una neurotoxina como el ácido kaínico. Las propiedades de los astrocitos presentes en ambos tipos de tejido gliótico son muy diferentes. Se han preparado membranas plasmáticas de astrocitos en reposo y reactivos a partir de tejido de cerebro no lesionado y tras una lesión que lo tornó gliótico (isomórfico o anisomórfico). Estas membranas se utilizaron como sustrato para estudiar el crecimiento en cultivo de axones de neuronas explantadas del SNC (hipocampo, septo, corteza cerebral, retina o médula espinal). Este modelo de cultivo puede ser manipulado para medir separadamente: a) el efecto de estas membranas (o sus componentes) sobre la adhesión neuronal al sustrato elegido; b) la iniciación y velocidad de crecimiento de las neuritas, y c) el efecto de atracción, repulsión o indiferencia de la neurita hacia el sustrato sobre el que crece [24]. La actividad inhibitoria presente en membranas plasmáticas derivadas de tejido gliótico isomórfico resistió el calor $\left(100^{\circ} \mathrm{C}, 20 \mathrm{~min}\right)$ y la digestión con tripsina y con glicosidasas. Fue, sin embargo, destruida por tratamiento con condroitinasa $\mathrm{ABC}$, heparitinasa o una mezcla de glucuronidasa y hialuronidasa. La actividad residía, por lo tanto, 
en un proteoglicano. Moléculas promotoras e inhibidoras de la neuritogénesis coexisten en el tejido gliótico, tanto isomórfico como anisomórfico, como indica el hecho de que membranas glióticas tratadas con detergente iónico débil y centrifugadas produzcan un sedimento insoluble muy neuritogénico y un sobrenadante muy inhibitorio, incluso en presencia de laminina. Ni el origen del tejido gliótico (hipocampo, corteza parietal, médula espinal), ni el de las neuronas embrionarias diana (hipocampo, giro dentado, septo, cuerpo estriado, corteza cerebral), ni el tipo de lesión parecen tener una importancia primaria determinante. Ambos tipos de tejido gliótico, isomórfico y anisomórfico, contienen actividades promotoras e inhibidoras de la neuritogénesis. Difieren en la proporción entre ambas, balance que determina la actividad expresada por las membranas [24]. La purificación del proteoglicano inhibidor (PGI) se llevó a cabo a partir de membranas plasmáticas de hipocampo gliótico (10 a 60 hipocampos), aprovechando su solubilidad en detergente débil [22] y su interacción diferencial con resinas de intercambio iónico en 0,1\% CHAPS y 7 M urea. La elución con solución de $\mathrm{NaCl}$ permitió separar glucosaminoglicanos (GAG) de distinta acidez, con actividades promotoras e inhibidoras del crecimiento de neuritas. El proteoglicano inhibidor impidió la iniciación de conos de crecimiento de neuronas de hipocampo embrionario, y a una concentración de 80 ng proteína/mL causó el colapso de conos de crecimiento y neuritas iniciados por laminina. Fracciones similares, obtenidas a partir de membranas de hipocampo no lesionado, no presentaron actividad inhibitoria. El peso molecular del PGI es 160-220 kDalton, de los que 48-50 kDalton corresponden a proteína y el resto a glicosaminoglicanos de tipo heparansulfato y condroitinsulfato. La porción proteica de PGI no presentó actividad alguna y toda la actividad inhibidora se observó en la porción de GAG. Anticuerpos monoclonales contra PGI permitieron su localización celular. En tejido normal, PGI se encontró exclusivamente en neuronas, mientras que en tejido lesionado se observó solamente en astrocitos reactivos fibrosos [23]. El inhibidor de la 'cicatriz glial' que hemos descrito es diferente de otros agentes inhibidores o capaces de colapsar conos de crecimiento, en particular el componente inhibitorio de la mielina. El PGI es probablemente la molécula responsable de la inhibición clásica observada por Ramón y Cajal en la 'cicatriz glial'. Los astrocitos reactivos siguen siendo los principales sospechosos de inhibir la regeneración axonal en los mamíferos. Queda por ver si el anticuerpo monoclonal anti-PGI, que bloquea la actividad inhibidora, actúa in vivo inhibiendo la inhibición, es decir, permitiendo el crecimiento de fibras regenerativas.

\section{LAS INSTRUMENTOS DE REPARACIÓN Productos que reducen la muerte neuronal secundaria}

Las lesiones del SNC y la perturbación de la barrera hematoencefálica con infiltración leucocitaria que la sigue disparan la liberación de una cascada de moléculas (citocinas proinflamatorias, radicales libres de oxígeno y nitrógeno, metabolitos del ácido araquidónico, aminoácidos excitatorios, ácido quinolínico, proteasas), que actuando sinergística o separadamente, causan la muerte neuronal secundaria. La contrapartida es la liberación concomitante de factores neuroprotectores, antinflamatorios, antioxidantes, neurotróficos y neuritogénicos. En la zona de penumbra, factores favorecedores e inhibidores de la supervivencia neuronal, de la degeneración y regeneración axonal, coexisten en equilibriodinámico.Laestrategiabásica para favorecer la reparación funcional del SNC es la modificación de este equilibrio en favor de los procesos de neurorreparación. El tratamiento de lesionados poco después del trauma debería ser realiza- do por personal paramédico, sin necesidad de cirugía; es decir, por administración preferiblemente parenteral, de sustancias que bloqueen o disminuyan la muerte neuronal secundaria. Los candidatos hasta el momento son los antagonistas de neurotransmisores excitatorios, los compuestos que inhiben la formación de radicales libres (antioxidantes) y los factores neurotróficos.

Un compuesto cuyo uso ha sido aprobado por la administración de los EE.UU. es la metilprednisolona, un esteroide supuestamente capaz de reducir la muerte neuronal secundaria. Parece existir una correlación positiva entre menor infiltración de leucocitos ED1 positivos y mayor preservación de tejido medular [26]. Al reducir el edema y la infiltración leucocitaria, la metilprednisolona reduce los niveles de peroxidación [27] y preserva más tejido medular [28]. Es probable que estos efectos del fármaco reflejen su interacción con el receptor de glucocorticoides expresado por células del parénquima medular. El receptor es detectable en el parénquima 15 minutos tras una contusión, aumenta su expresión hasta el máximo 8 horas después de la lesión y retorna a valores basales tres días más tarde. Los receptores de glucocorticoides están localizados, durante su expresión máxima, en las membranas de las motoneuronas (en las dendritas y el soma), de los oligodendrocitos, de los astrocitos y de las células endoteliales [29]. La activación de los receptores de glucocorticoides inhibe la acción del factor de transcripción NF- $\mathrm{KB}$ que, a su vez, regula la expresión de genes de citocinas proinflamatorias [30], justificando así las propiedades antinflamatorias y neuroprotectoras de la metilprednisolona.

Los antagonistas de glutamato, el neurotransmisor excitatorio principal en el cerebro y la médula espinal, han sido ensayados como inhibidores de la muerte neuronal secundaria. El glutamato actúa sobre receptores de varias clases, regulando la abertura de canales iónicos. El aumento poslesión en la concentración de aminoácidos excitatorios hasta niveles excitotóxicos y la subsecuente elevación en la concentración de $\mathrm{Ca}^{2+}$ intracelular son, oficialmente, los responsables de la muerte neuronal secundaria [20]. Entre los antagonistas de los receptores de glutamato tipo NMDA se encuentran la dizocilpina o compuesto MK801, el cerestat, la galiciclina y la memantina. El compuesto MK-801 es uno de los antagonistas más potentes de este receptor. Este fármaco prometedor parecía detener la muerte neuronal secundaria a concentraciones muy bajas, atravesaba libremente la barrera hematoencefálica y podía, por lo tanto, ser inyectado a víctimas de accidentes por personal paramédico. Sin embargo, el compuesto MK-801 presenta dos limitaciones serias: 1 . Su eficacia como neuroprotector es limitada, aunque su acción podría ser sinergística con la de los inhibidores de la formación de radicales libres; 2 . Sus efectos secundarios varían en gravedad, desde la inducción de episodios psicóticos a la inducción de neurodegeneración. Su uso clínico se ha interrumpido.

Otros antagonistas similares están siendo sometidos a ensayo clínico, con las advertencias indicadas al comentar la muerte neuronal retrasada, respectoal examen independiente de los distintos agentes neurotóxicos generados por la lesión. El uso separado de bloqueadores de receptores de Glu, de inhibidores de canales de $\mathrm{Ca}^{2+}$, tamponadores de $\mathrm{pH}$, o reductores de radicales libres, posiblemente siga teniendo escaso éxito, tanto clínico como experimental. El problema necesita ser tratado de forma global, teniendo en cuenta el estado funcional y metabólico de los tejidos implicados, incluyendo neuronas, glía y capilares sanguíneos [16]. El tejido neural en la zona de penumbra está en situación pre mortem, un estado casi estable que se mantiene como el tejido sano, es decir, con actividades metabólicas y funciones celulares. Las variables que desempeñan un papel en este estado 'lesionado' del tejido y su interdependencia son las 
mismas que operan en el tejido sano, basadas en los mismos principios fisicoquímicos, pero con otros valores. Uno de los rasgos identificativos más notables del tejido afectado es su despolarización celular masiva, debida a la alta concentración extracelular de $\mathrm{K}^{+}$. Pero el tejido en penumbra aún no está muerto y conserva su integridad física y funcional. Las menciones clásicas a la pérdida de integridad funcional de la membrana y, consecuentemente, de los gradientes iónicos, no parecen ser correctas. La resistencia eléctrica de la membrana de las neuronas no se pierde totalmente [31] y en las células gliales apenas es afectada. Los gradientes iónicos transmembrana disminuyen, pero no se pierden [32]. El estado lesionado es un estado cuasi estable, que se manifiesta por la presencia de un potencial eléctrico extracelular negativo de gran magnitud (superior a 15 milivoltios). Puesto que el tejido muerto no genera tales potenciales, este potencial eléctrico constituye quizás el signo 'vital' más característico. Potenciales eléctricos estacionarios de gran magnitud se observan tanto en el núcleo isquémico/traumático de agresiones focales, como en regiones sometidas a anoxia completa, choque hipoglucémico, y también como ondas transitorias propagadas a través del tejido tras diversos daños puntuales (p. ej., traumatismos), en la zona de penumbra isquémica o precediendo a la migraña clásica (depresión de Leao, DL). Este tipo de despolarización, de carácter tisular y cooperativo, no se observa en células aisladas.

La despolarización suele considerarse consecuencia de la pérdida de integridad de la membrana plasmática celular, con las consecuentes entradas de electrolitos y agua, hinchamiento y muerte. Por si esto fuera insuficiente, favorecida por la despolarización, la entrada de $\mathrm{Ca}^{2+}$ a través de canales voltajedependientes o asociados al receptor de glutamato tipo NMDA pondría en marcha mecanismos de muerte retrasada. Esta teoría excitotóxica o sus variantes (mayor papel de algunos metabolitos, como el ácido araquidónico, de los radicales NO, etc.) representan la creencia dominante. Sin embargo, estas teorías no permiten una distinción clara entre muerte por agresión focal o generalizada. Además, son incompatibles con hechos biofísicos bien conocidos y plantean preguntas de difícil respuesta. Por ejemplo, no pueden explicar la acción tóxica del glutamato sobre membranas totalmente despolarizadas, actuando sobre receptores necesariamente inactivados e induciendo la entrada de iones $\mathrm{Ca}^{2+}$ a través de canales voltajedependientes también inactivados. Pero, sobre todo, ¿por qué afectan a unos tipos neuronales y no a otros?

Durante mucho tiempo, los potenciales negativos habían sido atribuidos a la actividad sincicial de la red de astrocitos, presumiblemente por su acción drenando el $\mathrm{K}^{+}$intercelular acumulado [33]. Sin embargo, las neuronas tienen un papel fundamental en la generación de estos potenciales asociados a estados de riesgo [34,35]. El cambio de protagonista ha permitido ofrecer explicaciones alternativas a ciertas paradojas y abrir nuevas perspectivas. Las ondas DL fueron consideradas inocuas en tejido sano durante mucho tiempo, si bien se les atribuyó un papel agravante de la penumbra isquémica, acelerando el gasto energético [36]. Esa inocuidad, basada en supervivencia histológica, ha sido refutada, mostrando que en tejido sano provocan la pérdida (reversible) de capacidad electrorregenerativa durante varias horas [37]. Más aún, en tejido comprometido metabólicamente, las ondas DL causan un daño rápido e irreversible, que depende del estado de la red glial [38]. Las ondas DL no sólo matan neuronas a su paso por una región con función glial disminuida, sino que la hipofunción glial es suficiente para iniciar eventos idénticos a los observados en el núcleo y penumbra de un foco isquémico. Esos eventos incluyen la generación de ondas DL en la interfase entre núcleo y penumbra y la extensión gradual del primero en la segunda, provocado por el paso de las ondas [38,39]. Para salvaguardar la zona de penumbra es necesario detener su propagación. ¿Cómo detenerla? Las teorías de propagación mediada por un frente de onda excitador $\left(\mathrm{K}^{+}\right.$o Glu) parecen incorrectas y probablemente la propagación sigue una vía intercelular, a través de uniones eléctricas neuronales [35,40]. Es importante destacar que este tipo de despolarización masiva es un fenómeno 'todo-nada', que conlleva un cambio radical en casi todas las variables celulares y tisulares [41]. La interpretación de Herreras et al es que la entrada de $\mathrm{Ca}^{2+}, \mathrm{Na}^{+}, \mathrm{Cl}^{-}$y agua, la salida de $\mathrm{K}^{+}$y de $\mathrm{Glu}$, la acidificación, etc., son consecuencias y no causas de las ondas DL. La misma interpretación se aplicaría a la despolarización anóxica en la isquemia generalizada y en el núcleo isquémico, que presentan un escenario casi idéntico [32]. La duración de este estado es la variable mejor correlacionada con la recuperación electrorregenerativa neuronal [37]. Una hipótesis optimista es que la despolarización de tipo DL es un puente hacia la muerte neuronal, un estado reversible si se permanece en él durante un tiempo moderado y el tejido conserva intacta la función glial. Este estado se hace extremadamente frágil en caso contrario y sólo si la despolarización se reduce o acorta aumentará la supervivencia, independientemente del tratamiento a que se someta el tejido.

El hallazgo de la resistencia del tejido a la anoxia tras su precondicionamiento con una simple onda DL por 20-30 segundos [42] es especialmente relevante en este contexto. Evidentemente el estado de las células durante las ondas DL conlleva cambios sutiles, algunos de los cuales implican también funciones subcelulares requeridas para iniciar la denominada muerte programada o apoptosis. El punto común entre ondas DL y la anoxia está, de nuevo, en la despolarización de tipo DL. Durante mucho tiempo se ha buscado sin éxito una explicación de la muerte retrasada basada en cambios persistentes de la actividad neuronal tras la isquemia. Uno se sorprende cuando realiza el seguimiento de la fisiología neuronal tras uno de estos episodios. Tras un período de recuperación de unas horas, todo parece normal durante 2-3 días, y de pronto, sin previo aviso, la capacidad electrorregenerativa decae, continua e irreversiblemente, sin causa aparente [43, Herreras y Carceller, resultados sin publicar]. Después, las células mueren. Llega el tiempo de estudiar el aspecto de las células muertas, una actividad sólo útil para contribuir a la pugna apoptosis/citotoxicidad, una discusión técnica entre enterradores, con sus vaivenes y redefiniciones. Posiblemente el estudio del momento crítico proporcionará una información más valiosa. Ese momento, señalado por una despolarización de tipo DL, indica un estado celular/tisular diferente con características homeostáticas propias que hasta ahora hemos considerado como la manifestación incontrolada de un desastre.

\section{Glía de los sistemas regenerativos}

Dos lugares bien estudiados del SNC de los mamíferos donde los axones lesionados son capaces de regenerarse espontáneamente son el sistema hipotálamo-neurohipófisis y el bulbo olfatorio. La regeneración parece posible en estos sitios porque los axones están asociados a un tipo de macroglía promotora del crecimiento, similar a las células de Schwann periféricas, llamada glía envolvente (GE) en el bulbo olfatorio, tanicitos ( $\tan$ ) en el hipotálamo y pituicitos (pit) en la neurohipófisis. Esta glía ha sido cultivada y sus propiedades de crecimiento y marcadores de superficie específicos caracterizados, así como su interacción en cultivo con distintos tipos axonales [44,45].

La GE, los tanicitos y los pituicitos presentan similaridades y diferencias con los precursores de macroglía convencional del SNC. 
Sus inmunofenotipos (Tabla I) muestran similaridad a los prooligodendrocitos O4-positivos que persisten en el adulto [46] aunque, considerando el conjunto de sus marcadores inmunológicos, sus propiedades de proliferación y promoción del crecimiento axonal y su interacción con las neuronas, su mayor similaridad es con las células de Schwann. Tanicitos y pituicitos son frecuentemente considerados astroglía, con la que comparten lugar de origen ontogénico e inmunorreactividad para GFAP [47] y proteína S100. Sin embargo, tanicitos y pituicitos presentan inmunorreactividad para el receptor de NGF de baja afinidad, la proteína p75, en contraste con los astrocitos, pero en común con las células de Schwann [48] y la glía envolvente [49]. Asimismo, en contraste con los astrocitos, tanicitos y pituicitos muestran inmunorreactividad para los antígenos sulfátido y seminolípido, reconocidos por el anticuerpo monoclonal O4 en células de linaje oligodendrocítico [50], células de Schwann [50] y glía envolvente [51]. Otras propiedades fisiológicas de la GE, tan y pit, como su capacidad de envolver paquetes de axones no mielinizados [52-54], son asimismo reminiscentes de las propiedades de las células de Schwann no mielinizantes. Lo son también sus propiedades promotoras del crecimiento, lo que explica la regeneración eficaz de los axones periféricos [55], los axones olfatorios [56-58], los hipotalámicos [59-63], así como la promoción por trasplantes de GE de la reparación y mielinización de fibras nerviosas del SNC lesionado de la rata [12,64-68].

Desde el punto de vista de su biología celular, además de su capacidad de supervivencia y división en cultivo, las células de Schwann, la GE, los tanicitos y los pituicitos de mamíferos adultos muestran otros rasgos comunes, típicos de células en desarrollo. Por ejemplo, poseen un citoesqueleto inmaduro, con fuerte inmunorreactividad para vimentina [69], así como marcadores de motilidad y migración, como son las moléculas de adhesión de células neurales polisialiladas, PSA-NCAM [70,71] y el receptor de NGF, p75 [72,73]. PSA-NCAM no se expresa o su expresión es muy baja en astrocitos maduros, pero es abundante en la GE adulta [74] y la glía hipotalámico-neurohipofisiaria [75,76]. Además, anticuerpos contra los dominios $\mathrm{D}$ y $\mathrm{F}$ del receptor de estrógenos de tipo $\alpha$ tiñen el núcleo de las neuronas hipotalámicas [77-79], así como procesos citoplásmicos de las células de Schwann [80], GE, tanicitos y pituicitos, pero no los astrocitos [81]. El anticuerpo policlonal contra el receptor de estrógenos de tipo $\alpha$ suministrado por el National Hormone and Pituitary Program (NHPP, EE.UU.) fue preparado contra un péptido sintético del dominio $\mathrm{D}$ de ese tipo de receptor. La homología entre la secuencia del péptido y la del receptor de estrógenos está restringida a los aminoácidos 274-276 y 280 en el receptor de tipo $\alpha$ y a residuos $186-188$ y 192 en el receptor de tipo $\beta$, lo que hace improbable la reactividad cruzada.

La colocalización de las inmunorreactividades para el receptor de estrógenos de tipo $\alpha$ y el receptor de neurotrofinas de baja afinidad p75 [82] podría ser determinante de las propiedades de este tipo de glía. Las neurotrofinas y su receptor p 75 participan en la regulación endocrina, particularmente de los estrógenos [83]. Los receptores de estrógeno son factores de transcripción y el sistema de señalización NGF/p75 implica la activación de NF- $\kappa B$ [73]. Aunque la activación de p75 por NGF está generalmente asociada a apoptosis, NF- $\kappa \mathrm{B}$ es un regulador de la expresión de muchos genes, alguno de los cuales suprime la apoptosis [84] y potencia la longevidad [85]. Los estrógenos también inhiben la apoptosis [86] y la expresión concomitante de receptor de estrógenos de tipo $\alpha$ y NF- $\kappa B$ por las células gliales antes mencionadas, puede conferirles los rasgos de inmadurez observados y su capacidad para entrar en el ciclo de división celular. Las señales
Tabla I. Marcadores inmunológicos de tanicitos, pituicitos, GE, astrocitos, oligodendrocitos y células de Schwann

\begin{tabular}{lcccccc}
\hline & O4 & p75 & S100 & RE & Vim. & GFAP \\
\hline Tipo celular & & & & & & \\
\hline Ast. $^{b}$ & - & - & + & - & - & ++ \\
\hline Olig. $^{\text {b }}$ & ++ & - & \pm & - & - & - \\
\hline SC $^{c}$ & + & ++ & ++ & ++ & ++ & ++ \\
\hline Tan $^{b}$ & + & + & ++ & ++ & ++ & ++ \\
\hline Tan. $^{c}$ & + & ++ & ++ & + & ++ & + \\
\hline Pit. $^{b}$ & + & + & ++ & ++ & ++ & ++ \\
\hline Pit. $^{c}$ & + & ++ & ++ & + & ++ & + \\
\hline GE $^{b}$ & + & + & ++ & + & ++ & ++ \\
\hline GE $^{c}$ & + & ++ & ++ & + & ++ & + \\
\hline Cainm $^{b}$ & & + & & & + & + \\
\hline
\end{tabular}

La inmunorreacción histoquímica fue: $(++)$ positiva y muy fuerte; $(+)$ claramente positiva; $(-)$ negativa Lareactividadcon los marcadoresinmunológicosindicados positiva; (-) negativa. La reactividad con los marcadores inmunológicos indicados fue examinada: en tejido adulto in situ ${ }^{\mathrm{b}}$; en cultivos preparados a partir de tejido adulto ${ }^{c}$. Astrocitos (Ast.), oligodendrocitos (Olig.) y células de Schwann no mielinizantes en cultivo (SC) se utilizaron como estándar de intensidad de inmunotinción en las mismas condiciones experimentales que las otras células. Tan. tanicitos; Pit.: pituicitos; GE: glía envolvente; O4: antígeno O4, seminolípido, sulfotido; p75: receptor de neurotrofinas de baja afinidad; S100: proteína S100; RE: receptor de estrogeno de tipo a, Vim... vimentina, GFAP. proteina acida de los filamentos gliales (IgG policlonal). " La inmunotinción de secciones de tejido con el anticuerpo anti-S100 policlonal no fue selectiva, es decir, todos los tipos de glía mostraron una tinción débil junto con la intensa tinción de GE o tanicitos.

de mitógenos, estrógenos y neurotrofinas pueden, hipotéticamente, serintegradas por la proteína CBP $(C R E B$ binding protein $[86,87])$ CBP puede regular la transcripción coordinada de múltiples genes e integrar la señalización por NGF y estrógeno en las células de Schwann [73]. En otras células neurales, la coexpresión de los receptores de estrógenos de tipo $\alpha$ y de neurotrofinas $\mathrm{p} 75$ produciría un fenotipo glial similar al de las células de Schwann.

En resumen, en lo concerniente a marcadores inmunológicos, capacidad de envolver neuritas, promover la regeneración y dividirse, GE, tanicitos y pituicitos se asemejan más a las células de Schwann no mielinizantes que a ningún otro tipo de macroglía del SNC. Pueden constituir una nueva población glial del SNC con propiedades especiales, estimuladoras de la plasticidad. Las relaciones progenitor-progenie han sido establecidas por cultivo celular en medio definido, junto con marcadores inmunológicos, Pero, definitivamente, esta metodología tiene limitaciones. Por ejemplo, varios marcadores de linaje celular utilizados en el trabajo de $\mathrm{Gu}$ diño-Cabrera y Nieto-Sampedro [82], agruparían células de Schwann, GE, tanicitos y pituicitos en el mismo linaje y estadio ontogénico. Sin embargo, las células de Schwann se originan en la cresta neural [88], la GE en la placoda olfatoria [89,90] y tanicitos y pituicitos derivan, como astrocitos y oligodendrocitos, de la zona subventricular [91]. Nuestro trabajo, publicado junto con observaciones similares sobre la glía perivascular, las células de Müller retinianas y la glía pineal [Gudiño-Cabrera y Nieto-Sampedro, observaciones no publicadas], plantean dudas sobre el valor definitivo de los marcadores inmunológicos para establecer el linaje glial. Las células mencionadas anteriormente comparten marcadores inmunológicos específicos, propiedades de proliferación y promotoras del crecimiento, pero tienen linajes distintos, bien establecidos. Aunque el antígeno $\mathrm{O} 4$ es un marcador específico de prooligodendrocitos en un estadio ontogénico posterior al de los precursores 


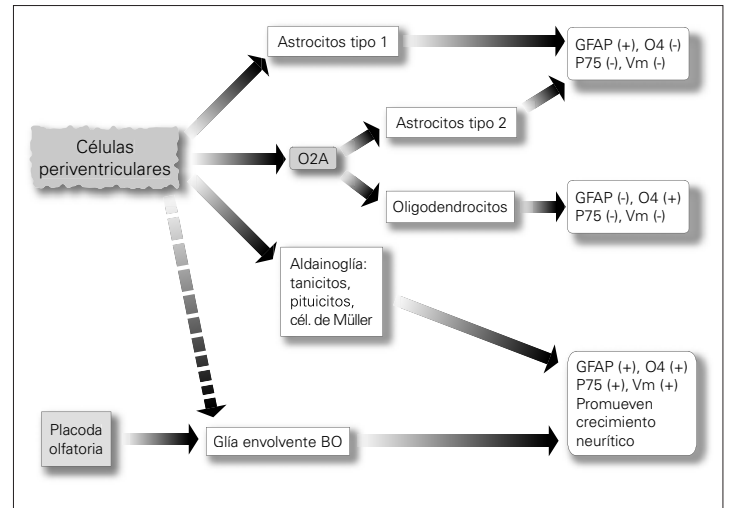

Figura 1.

O2-A [92] y persisten en el adulto prooligodendrocitos O4-positivos, capaces de división [92-94], tanicitos, pituicitos y GE no son precursores. Cada uno de estos tipos de célula es abundante en el sitio anatómico donde se encuentra y desempeña un papel fisiológico preciso en el adulto. Las células parecen morfológica, funcional e inmunológicamente homólogas entre sí y a las células de Schwann no mielinizantes y, junto con las células de Müller y de Bergmann inmaduras y junto con otros tipos de glía radial joven y ontogenia diferente [95], parecen constituir un tipo de macroglía central diferente y único. En vista de su capacidad de crecer e inducir el crecimiento, la hemos denominado aldainoglía, del griego ' $\alpha \lambda \delta \alpha \iota \nu \omega$ ' (hacer crecer). La aldainoglía constituye un tipo de macroglía distinto de astrocitos y oligodendrocitos y comparte propiedades funcionales y estructurales (Fig. 1). Se caracteriza por la expresión simultánea de p75, del glicolípido O4, del receptor de estrógenos de tipo $\alpha$, vimentina y GFAP. Aunque es diferente de los astrocitos, la aldainoglía es frecuentemente mal llamada astroglía. Está implicada en la regeneración axonal que ocurre espontáneamente en el adulto, apoyando la idea de que necesidades biológicas similares provocan una expresión génica similar en sistemas biológicos diferentes. Éste es el caso, por ejemplo, de la necesidad de renovación continua de las neuronas olfatorias, de los receptores sensoriales o de los axones secretores hipotalámico-hipofisiarios.

La GE tiene capacidad per se para promover la regeneración axonal. Ésta es una propiedad que no se expresa exclusivamente en la región anatómica donde se encuentra normalmente la GE. Verdú et al demostraron que la GE tiene efectos promotores del crecimiento de nervios periféricos comparables o superiores a las células de Schwann [96]. El nervio ciático de la rata resectado se puede reparar uniendo los cabos proximal y distal con un tubo de silicona, si el espacio entre los cabos del nervio no supera los 10 $\mathrm{mm}$. La regeneración axonal no tiene lugar cuando la distancia entre los cabos reseccionados y unidos por el tubo es de $15 \mathrm{~mm}$, excepto si se incluye dentro del tubo una suspensión de GE. La GE permitió regenerar a los axones seccionados en un 50\% de los animales con un espacio reseccionado de $15 \mathrm{~mm}$. Resultados similares se obtienen incluyendo dentro del tubo una suspensión de células de Schwann y, aunque se puede especular que ambos tipos de glía presentan capacidades similares para promover la regeneración axonal [97], una comparación directa entre ambos tipos de célula aún no se ha llevado a cabo en el mismo modelo animal. Una ventaja obvia de utilizar células de Schwann para reparar el sistema nervioso periférico es la posibilidad de autotrasplante, que en el caso de la GE es mucho más problemático. Nuestros resultados apoyan que el efecto promotor de la regeneración axonal de la GE es debido a sus propiedades intrínsecas [98], condicionadas por su migración orientada en el SNC [99].

El uso terapéutico de la aldainoglía para la reparación de lesiones del SNC requiere conocer su comportamiento in vivo; lo que, a su vez, plantea la necesidad de su trasplante sistemático en regiones del SNC donde la regeneración espontánea no ocurre, y la observación de los tipos axonales que pueden ser reparados con su ayuda.

\section{AVANCES EN REPARACIÓN NEURAL Reparación de lesiones experimentales en las raíces posteriores}

La incapacidad de la rama central de las neuronas del ganglio raquídeo para volver a entrar en la médula espinal después de una lesión ya fue descrita por Cajal en 1914. El daño a las raíces dorsales causa degeneración walleriana (anterógrada [100,101]), acompañada de gliosis reactiva. La rama central de las neuronas sensoriales separada del soma es rodeada por microglía ameboide [102] y astrocitos reactivos [103], que contribuyen a la fagocitosis de los terminales axonales en degeneración [104,105]. La glia reactiva aparece antes de la llegada de los brotes axonales regenerativos y forma una barrera inhibitoria que no puede ser cruzada por los axones sensoriales. Los brotes forman terminales sinaptoides con los astrocitos en la frontera entre los sistemas nerviosos periférico (SNP) y central [106-108]. La irradiación de la médula espinal dorsal hace posible que los axones sensoriales penetren en ella. Las células de Schwann migraron en este caso centralmente, hacia la zona de entrada de la raíz dorsal (DREZ), donde la irradiación eliminó astrocitos y oligodendrocitos [109] y ayudó al crecimiento de los aferentes sensoriales en la médula [110]. El trasplante de astrocitos restauró las propiedades inhibidoras del crecimiento de la frontera SNP/SNC [111] y, por contra, oligonucleótidos antisentido que inhiben la síntesis de GFAP convirtieron a los astrocitos inhibitorios en células promotoras del crecimiento axonal [112].

Varias moléculas inhibidoras, principalmente proteoglicanos sulfatados en astrocitos reactivos [10,22,113-118] y tenascina [119] se concentran en la DREZ y en áreas cercanas del asta dorsal tras lesiones en la raíz dorsal [9] y pueden detener la penetración en la médula de brotes axonales regenerativos. La inhibición del crecimiento de neuritas sensoriales por membranas plasmáticas de tejido gliótico del SNC fue revertida por preincubación con enzimas capaces de degradar proteoglicano in vitro [22,24] e in vivo [120]. Otras moléculas inhibitorias asociadas a la mielina en la sustancia blanca de la DREZ y en la banda de Lissauer también contribuyen significativamente a obstaculizar la regeneración $[8,21,121,122]$. Por último, los efectos quimiorrepelentes de moléculas específicas de guía axonal, como semaforinas, slits o efrinas, desempeñan también un papel importante en la regeneración a través de la DREZ. Así, en ratones transgénicos carentes del gen para semaforina III, los axones inmunorreactivos para el péptido relacionado con el gen de calcitonina (CGRP) frecuentemente inervan áreas fuera de su zona terminal normal, incluidos el canal central y el asta ventral [123]. Ciertamente el papel de éstos y de otros factores quimiotrópicos reguladores del crecimiento axonal recibirán atención preferente en el futuro inmediato.

En el hombre, las avulsiones de fibras sensoriales y varios grados de lesión periférica en los nervios del plexo braquial se asocian frecuentemente al parto en el recién nacido, así como a accidentes de 
trabajo, deportivos y de tráfico, especialmente con ciclomotores $[124,125]$. Estas lesiones causan graves déficit sensoriales, parálisis y dolor neuropático. Aunque puede alcanzarse una pequeña recuperación motora por neurotización secundaria con nervios intercostales u otros nervios periféricos, hasta ahora las lesiones no han podido ser reparadas, ya sea directamente o mediante trasplantes. Restaurar la función sensorial por crecimiento de los aferentes raquídeos en la médula sigue siendo todavía un problema sin respuesta clínica satisfactoria [126,127]. La reparación de la rama central del ganglio raquídeo T8 transectada en la rata adulta [12,128] fue, hasta donde conocemos, la primera regeneración en la médula espinal de axones en número suficiente para pensar en la recuperación de una función. La elección de la raíz T8 fue buena desde el punto de vista de la cirugía experimental. Sin embargo, el gran solapamiento sensorial no permitió examinar claramente ninguna consecuencia funcional. La pérdida mesurable de una función requiere rizotomía múltiple, lo que hemos llevado a cabo más recientemente, a niveles medulares desde cervical a sacro. A todos los niveles hemos encontrado crecimiento en la médula de las raíces sensoriales y suficiente reinervación de las dianas sinápticas adecuadas para mediar una recuperación funcional parcial, pero significativa. Con el fin de optimizar la recuperación de funciones mediada por los aferentes capaces de crecer en la médula tras rizotomía dorsal, hemos ensayado variaciones en la técnica quirúrgica y en el sitio de trasplante (Fig. 2). En los segmentos cervicotorácicos la suspensión de GE fue inyectada en el asta dorsal, en la zona de entrada de la raíz, unas decenas de micras por debajo de la banda de Lissauer. En el plano lumbar, la suspensión fue inyectada en el muñón de la raíz y en el caso de la deaferentación lumbosacra, en las cercanías del núcleo parasimpático sacro. En todos los casos la GE migró, tanto hacia el canal central como hacia la zona de entrada de la raíz dorsal ipsilateral [129]. También en todos los casos observamos regeneración parcial de numerosos axones y el conjunto de estos estudios mostró que el trasplante de GE induce la recuperación de las funciones sensoriales cutánea, proprioceptiva y autonómica.

\section{Restitución de la micción voluntaria}

La médula espinal es el primer escalón en la relación que mantenemos con el mundo exterior. Allí se integran los impulsos nerviosos procedentes de los diversos órganos y se elaboran los reflejos espinales, que están, a su vez, controlados por centros del tronco, el mesencéfalo y la corteza cerebral. Los traumas en la médula espinal pueden causar profundos cambios somatoviscerales que condicionan seriamente la vida del individuo. Históricamente, comenzamos por las raíces lumbosacras implicadas en el control de la micción $[65,130]$. La vejiga urinaria, al igual que otros órganos pélvicos, tiene una función de almacenamiento y evacuación periódica, en la que participan activamente la musculatura lisa del cuello vesical, la uretra y la musculatura estriada del esfínter uretral externo, así como los músculos del suelo pélvico. Sabemos que los sistemas espinales autónomo y somático participan en el reflejo miccional, pero la información disponible es parcial y, en algunos modelos experimentales, contradictoria [131]. Los reflejos bilaterales son muy importantes en el sistema autónomo sacro, porque un órgano efector único en la línea media (vejiga, pene, intestino grueso) recibe elestímulocoordinado de neuronas preganglionares de ambas zonas intermediolaterales de la médula espinal. Las dendritas contralaterales o las neuronas preganglionares pueden proporcionar un mecanismo para esta coordinación [132,133]. La mayoría de los aferentes vesicales son fibras delgadas mielinizadas (tipo A-delta) y no mielinizadas (tipo C), que llegan a la médula espinal lumbo-

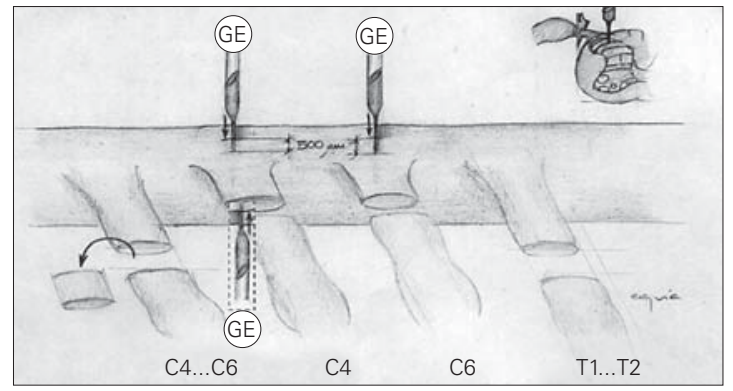

\section{Figura 2.}

sacra a través del nervio pélvico $[134,135]$. Conducen impulsos desde los receptores en la pared vesical hasta el núcleo parasimpático sacro (NPS) medular. Las neuronas de este núcleo, en la región intermediolateral de la médula espinal, coordinan la respuesta a la información que llega de los sistemas implicados en la micción. Existen datos en diversas especies animales, como el gato [134,136], el mono [140], el perro [142] y la rata [137-139], donde se han observado diferencias en la localización del NPS, dependientes de la cepa utilizada. La gran ventaja del modelo estriba en que la medida de la presión vesical y del volumen de orina retenido son medidas objetivas, poco susceptibles de discrepancia.

Los aferentes vesicales en la rata viajan en el tracto de Lissauer, penetran en los niveles medulares L6, S1 y S2 y se dividen en dos fascículos: uno lateral, prominente, que cursa por el borde del asta posterior y se dirige hacia las neuronas preganglionares del NPS en la lámina VII, y un fascículo medial, que proyecta hacia la comisura gris dorsal y la zona periependimaria que rodea al canal central, en la lámina X $[134,138,139]$. Las vías simpáticas, que proporcionan un tono inhibitorio al músculo detrusor y un tono excitatorio al cuello vesical a través de axones preganglionares desde los niveles medulares L1-L2, participan en la regulación de la actividad de la vejiga urinaria, mediante sinapsis en la cadena ganglionar paravertebral y en el ganglio mesentérico inferior [151]. Los axones posganglionares proyectan desde esos ganglios a través de los nervios hipogástrico y pélvico, mientras que los axones simpáticos preganglionares también proyectan a través del nervio hipogástrico para terminar en el ganglio pélvico [156]. La musculatura del suelo pélvico, el esfínter externo de la uretra, la uretra, el pene o clítoris y la piel perineal están inervados por el nervio pudendo, que es considerado un nervio típicamente somático.

El segmento medular donde están localizadas las motoneuronas que inervan esas estructuras ha sido determinado mediante trasporte retrógrado de peroxidasa (HRP) en la rata [129,143], el perro [144], el gato [145] y el mono [146,147]. Los aferentes que viajan en el nervio pudendo terminan en la zona lateral del asta posterior de la médula espinal, en las láminas I, V-VII y X, solapando parcialmente con los procedentes de la vejiga urinaria $[139,148,149]$. En la función vesical están implicados los tres sistemas nerviosos, parasimpático, simpático y somático [141], y una alteración en cualquiera de ellos perturba la integración medular de los reflejos que regulan la micción. Se han descrito dos reflejos fundamentales en la rata: uno supraspinal, que alcanza el centro pontino de la micción y representa el mecanismo neuronal fundamental en animales con una médula espinal intacta, y un segundo reflejo medular lumbosacro, que se encuentra en los animales con lesiones medulares crónicas y en un $25 \%$ de los animales intactos con reflejo de micción lento $[150,151]$. La interrupción de las vías que integran estos reflejos, 
generalmente por traumatismo medular, tiene como consecuencia el desarrollo de una vejiga neurógena, cuyo comportamiento funcional depende del nivel de la lesión: lesiones por debajo de L1 generalmente producen una vejiga neurógena sin tono, esto es, incapaz de vaciar, mientras que las lesiones medulares en L1 o superiores generalmente desarrollan vejigas hipertónicas que dan lugar a altas presiones intravesicales y a la aparición de incontinencia, reflujo vesicorrenal, etc., existiendo una pléyade de estados intermedios en lesiones completas e incompletas [152].

El estudio de las alteraciones en la función vesical derivadas de una lesión medular a cualquier nivel se realiza por medio de la urodinámica. Los estudios urodinámicos son claves en la urológica clínica cotidiana $[153,154]$ para diagnosticar alteraciones en el vaciado [155-158], así como para implantar estimuladores Finetech-Brindley en pacientes parapléjicos. La urodinámica también se aplica a modelos experimentales, donde la fisiopatología de situaciones clínicas puede ser reproducida y su correlación con la reparación nerviosa examinada [136,159-163].

El desarrollo de nuestro modelo de deaferentación vesical se basó en la caracterización electrofisiológica previa de las raíces lumbosacras de la rata [164-166]. Estos investigadores observaron que la estimulación eléctrica de la raíz ventral L6 causa un incremento marcado en la presión intravesical y en la presión intracavernosa, además de una respuesta esfinteriana, aunque es la estimulación de S1 la que produce el mayor incremento en la presión intravesical. En el animal intacto, la presión máxima se sitúa en torno a los $25 \mathrm{cmH}_{2} \mathrm{O}$, un valor por encima del cual se supera la presión de cierre uretral y escapa orina por el meato [167]. La deaferentación vesical experimental implica desgraciadamente una cirugía larga, compleja y sujeta a gran mortalidad [130]. En nuestro modelo en la rata, se realizó una laparotomía, seguida de la inserción de un catéter en la vejiga urinaria para infundir solución fisiológica y medir la presión vesical resultante. Tras rizotomía para exponer los segmentos medulares lumbosacros, las raíces dorsales que responden a los cambios en la presión vesical fueron identificadas por registro electrofisiológico. Una vez identificadas las tres raíces dorsales que contribuyen mayoritariamente a la inervación de la pared de la vejiga (L6, S1 y S2, o S1, S2 y S3, dependiendo del animal), éstas fueron seccionadas cerca de su entrada en la médula, lo que tuvo como resultado una vejiga neurógena. Un grupo de estas ratas recibió el trasplante en la proximidad del núcleo parasimpático sacro de unas 30.000 células de GE purificada por raíz seccionada. Las raíces seccionadas fueron adheridas con Tissuecol a la superficie medular, cerca de su sitio de entrada original. La pérdida y recuperación de los parámetros urodinámicos antes y después de la rizotomía y a tiempos intermedios tras el trasplante de GE nos proporcionaron información precisa sobre la recuperación de la micción voluntaria [130]. En las fases iniciales del registro, antes de activar la bomba de infusión de solución salina, se observaron generalmente picos de presión intravesical de unos minutos de duración, atribuidos a la excitación del músculo detrusor causada por la manipulación [150]. El mayor incremento en la presión intravesical ocurrió al estimular eléctricamente la raíz ventral S1, incremento que llegó a superar $\operatorname{los} 30 \mathrm{cmH}_{2} \mathrm{O}$, mientras que la estimulación de L6 y S2 causó incrementos variables similares a los registrados por otros autores y generalmente inferiores a 10 $\mathrm{cmH}_{2} \mathrm{O}[150,160,166]$. La estimulación de las raíces adyacentes no incrementó en ningún caso la presión intravesical, también de acuerdo con publicaciones previas [150,165].

Las aferencias parasimpáticas vesicales cambian también tras obstrucción de la uretra, posiblemente en respuesta a los cambios de actividad o concentración de factores neurotróficos en el órgano diana $[159,160]$. En la patología humana, la sobredistensión vesical producida generalmente por problemas obstructivos bajos causa una disminución transitoria de la noradrenalina y de neuropéptidos en la pared vesical $[167,168]$. En gatos con lesión crónica de la cola de caballo es posible la regeneración axonal en el esfínter estriado externo, mediante una sinapsis axo-axonal adrenérgicacolinérgica, que produce una disfunción del esfínter distal por alteración en el influjo simpático, lo que clínicamente se expresa en la obstrucción del flujo urinario [169]. En definitiva, el sistema nervioso periférico muestra gran capacidad para adaptarse a nuevas situaciones y su plasticidad puede generarse: a) por crecimiento axonal, similar al observado tras una lesión en la médula espinal o daño en los nervios periféricos; b) por cambios en la cantidad o tipo del neurotransmisor en los aferentes, y c) por alteraciones en el patrón de las aferencias implicadas [160]. Una diversidad de agentes parecen implicados en la respuesta plástica del sistema nervioso autónomo: factores neurotróficos, cambios en el trasporte axonal de neuropéptidos, alteraciones en el órgano diana, activación de vías silentes en condiciones fisiológicas normales, etc. Los axones lesionados en el sistema nervioso periférico son capaces de formar brotes, elongarse y contactar con sus dianas originales, aunque la experiencia clínica indica que la recuperación funcional lograda es insatisfactoria [170]. El número de axones que regenera, su diámetro, excitabilidad y velocidad de conducción, permanecen disminuidos durante largos períodos $[171,172]$, aunque el crecimiento hacia el órgano efector es una realidad y las terminales colinérgicas en el detrusor de la rata aumentan a partir de dos semanas posneurectomía [173].

Las lesiones de la médula espinal en la rata se han intentado reparar, con éxito funcional limitado, utilizando trasplantes de diversos tipos: de células de médula fetal [174,175], de células de Schwann cultivadas $[110,176]$ y de otros tipos de macroglía, como oligodendrocitos y astrocitos modificados [177-179]. En nuestro modelo experimental las lesiones fueron reparadas con trasplantes de GE cultivada, 95\% viable [44], trasplantada en el asta posterior de la médula espinal, a unas $800 \mu \mathrm{m}$ de profundidad, en la zona del NPS. Las células de GE, observadas seis semanas postrasplante por tinción inmunohistoquímica específica, se encontraron distribuidas en una amplia zona de la sustancia gris medular, junto con macrófagos inflamatorios del huésped. Las seis semanas postrasplante hasta el sacrificio de los animales permitieron la regeneración axonal y la recuperación parcial de la función vesical perdida tras la rizotomía. La inyección de lectina de germen de trigo unida a peroxidasa (WGA-HRP) en la pared de la vejiga y su observación por microscopia electrónica evidenciaron la formación de nuevas sinapsis en el NPS. En contraste, los controles deaferentados en los que no se trasplantó GE, ni recuperaron función alguna, ni los axones transectados regeneraron. Los brotes axonales captaron WGA-HRP y lo llevaron hasta la zona de entrada en el asta dorsal de la médula, pero no lograron penetrar en ella.

\section{Reparación sensitivomotora de las extremidades}

Los estudios de reparación de la inervación sensorial de las extremidades posteriores se iniciaron un año después. Los aferentes sensoriales viajan en el nervio ciático y la lesión experimental que los interrumpe es la rizotomía central de los segmentos L3 a L6, entre el ganglio raquídeo y la médula. En este caso dejamos un segmento de raíz de aproximadamente 3-5 mm unido a la médula en el que trasplantamos células de GE purificada [68].

El reflejo monosináptico de Hoffman (onda $\mathrm{H}$ o respuesta $\mathrm{H}$ ) ipsilateral a la estimulación del miembro posterior desapareció en 
todos los animales a la semana de la rizotomía. En el grupo de animales con trasplante de GE se registró en siete de 10 ratas, frente a una de 10 en el grupo de referencia a los 60 días postoperación. En ese mismo lapso de tiempo reapareció el reflejo de retirada en 4/10 ratas del grupo con GE. La GE trasplantada, premarcada con el trazador fluorescente PKH26, se observó en secciones histológicas de médula lumbar dos meses postoperación. Las células de GE se disponen en hileras, desde el asta dorsal hasta el canal central. En animales de grupos control presentaron una leve inmunorreactividad para CGRP en la zona de entrada de las raíces dorsales; por el contrario, en las ratas con trasplante de GE se observaron axones CGRP-reactivos regenerados en el asta dorsal, asociados a la GE trasplantada [68].

Los resultados de este estudio indicaron que la GE trasplantada en la zona de entrada de las raíces dorsales en la médula promueve la regeneración de la rama axonal central de estas neuronas sensoriales y que estos axones regenerativos forman conexiones sinápticas en la médula, que restituyen arcos reflejos espinales. Las respuestas reflejas reaparecieron en las ratas trasplantadas GE en un número significativamente superior a los grupos control, a los dos meses posrizotomía. Los axones regenerados llegan a las láminas medulares que inervan normalmente, siguiendo la vía de migración de la GE en la sustancia gris, explicando el restablecimiento de los circuitos reflejos espinales. La reaparición de distintos componentes de los reflejos correlaciona con la regeneración de los distintos tipos de aferente implicados (A $\alpha$ para el reflejo $\mathrm{H} ; \mathrm{A} \beta, \mathrm{A} \delta$ y Cpara los distintos componentes del reflejo de retirada $[180,181]$ ), indicando que todos ellos pueden regenerar con ayuda de GE trasplantada y formar las sinapsis apropiadas. Estudios electrofisiológicos previos en los que la rizotomía fue reparada con trasplantes de tejido nervioso embrionario, demostraron que las fibras aferentes regeneradas conducían con una velocidad similar a las fibras $C$, $\mathrm{A} \delta$ y $A \alpha / \beta$. La estimulación de las raíces lesionadas y regeneradas provocaba potenciales sinápticos en el tejido trasplantado, es decir, se formaban sinapsis funcionales con las neuronas trasplantadas [174,182], aunque los axones regenerados no volvían a penetrar en la médula del huésped [183].

Por último, hemos probado también la capacidad de trasplantes de GE para restituir parcialmente la movilidad del miembro superior. La rizotomía dorsal se extendió desde el segmento cervical C3 hasta el torácico T2, para producir la denervación completa del miembro anterior. Con el fin de comprobar, por una parte, que la recuperación funcional puede obtenerse con la mínima intervención quirúrgica, y por otra, que está mediada por fibras sensoriales seccionadas y regeneradas y no por brotes reactivos de las raíces adyacentes, el trasplante de GE se limitó a las raíces $\mathrm{C} 7$ y C8, las contribuyentes mayoritarias al nervio mediano. Se cree que la contribución de brotes de raíces no dañadas rostrales o caudales a una rizotomía múltiple como la utilizada en nuestro modelo experimental [184] es muy escasa o nula [185-188]. La regeneración de los aferentes dañados parece ser el contribuyente principal a la recuperación funcional observada. Nuestros estudios combinados muestran que trasplantes de GE inducen la recuperación de las funciones sensoriales cutánea, proprioceptiva y autonómica. El crecimiento axonal permite la reinervación del asta dorsal y la activación de neuronas postsinápticas con restitución de la actividad refleja polisináptica. La recuperación electrofisiológica se tradujo a nivel conductual por el restablecimiento del reflejo de retirada tras estimulación de las extremidades y en respuestas supraespinales nocifensivas organizadas.

La rizotomía dorsal unilateral múltiple $\mathrm{C} 4$ a T2 produce déficit sensoriales graves en la extremidad anterior de la rata, déficit que el trasplante de GE en la zona de entrada de las raíces dorsales C7/ C8, redujo significativamente [184]. La inducción de la proteína $c$-fos es una respuesta a estímulos nocivos en las neuronas del asta dorsal de animales sanos [189], que se pierde tras la rizotomía [185]. Las ratas rizotomizadas que recibieron trasplantes de GE en $\mathrm{C} 7$ y $\mathrm{C} 8$ recuperaron la inducción de $c$-fos [184]. Es decir, el trasplante de GE hizo posible la recuperación de contactos funcionales entre los axones sensoriales lesionados y las neuronas del asta posterior.

La recuperación de la función de los circuitos que permiten los reflejos cutáneos se comprobó directamente registrando la actividad refleja del bíceps en respuesta a la estimulación del nervio mediano que lo controla. Las ramas centrales de las raíces dorsales C4 a T2 que contribuyen a la inervación sensorial del miembro anterior fueron seccionadas a su entrada en la médula. La GE fue trasplantada en el asta dorsal ipsilateral, en la zona de entrada de las raíces $\mathrm{C} 7 / \mathrm{C} 8$, por debajo de la banda de Lissauer (Fig. 2). Dos meses después comparamos ratas no operadas, animales rizotomizados y trasplantadas por medio de cultivo celular y ratas rizotomizadas y trasplantadas GE purificada en cuanto a crecimiento de proyecciones específicas en el asta dorsal, uso de la extremidad para manipular objetos y curvas estímulo-respuesta de contracción del bíceps en respuesta a la estimulación del nervio mediano. Las raíces seccionadas volvieron a crecer solamente en la médula de los animales que recibieron trasplantes de GE, que fueron los mismos que recuperaron parcialmente el uso de su extremidad superior. Registros electrofisiológicos del bíceps en respuesta a la activación del nervio mediano, con pulsos de duración corta $(0,1 \mathrm{~ms})$ o larga $(0,5 \mathrm{~ms})$, permitieron concluir que, en efecto, hubo regeneración parcial: solamente las fibras aferentes de pequeño diámetro regeneraron en los animales trasplantados. Los reflejos recuperados del bíceps tras el trasplante de GE muestran una 'ganancia' superior tanto a los de ratas normales como a los de ratas rizotomizadas y no trasplantadas. La rizotomía o la rizotomía más trasplante de medio de cultivo condujo a la pérdida de la descarga electromiográfica sincrónica provocada en el bíceps por estimulación del nervio mediano de ratas adultas sanas. Por el contrario, en animales donde la rizotomía múltiple fue seguida del trasplante de GE, una estimulación similar seis meses después de la operación provocó en el bíceps una descarga electromiográfica asincrónica.

La recuperación sensorial observada por electrofisiología ocurrió en paralelo con la restauración de los reflejos sensoriales en el animal despierto. El reflejo de retirada a un estímulo nocivo (calor radiante) y la respuesta nocifensiva supraespinal tanto a estímulos térmicos como mecánicos, aplicados a la palma de la pata delantera ipsilateral, fueron medidos antes y hasta dos meses después de la rizotomía dorsal cervical. El reflejo de retirada a estímulos térmicos aplicados a la pata delantera se recuperó significativamente en animales trasplantados GE, en contraste con la ausencia de respuesta a estímulos mecánicos tanto en controles trasplantados por medio de cultivo, como en el grupo trasplantado GE. Durante el primer mes posrizotomía, las respuestas reflejas de retirada ipsilaterales desaparecieron en los grupos de referencia y experimental, para reaparecer con significancia estadística en el grupo trasplantado GE, en el segundo mes postoperación. El test de retirada de la pata delantera del calor radiante se utilizó también para medir la recuperación de la respuesta nocifensiva en animales trasplantados, una respuesta supraspinal organizada, pero no aprendida. Utilizando una escala definida no paramétrica, valoramos la respuesta al calor radiante en la palma de la pata delantera orientando la cabeza hacia la pata y lamiéndola. Los valores en esta escala cayeron desde un valor máximo de ' 3 ' en animales normales a un valor de ' 0 ' tras la rizotomía múltiple. El valor ' 0 ' no cambió en controles que no 
recibieron GE, circunstancia que indica la ausencia de orientación de la cabeza hacia la pata ipsilateral y de contacto con ella en respuesta a la estimulación térmica. En contraste, el grupo de ratas trasplantadas GE recuperaron un valor de ' 1 ' durante el segundo mes postrasplante. El desarrollo de estas respuestas nocifensivas supraespinales tras la implantación de GE se correlacionó significativamente con la recuperación de la actividad flexora de retirada, indicando que ambos comportamientos, la actividad refleja y la respuesta supraespinal, están mediados por aferentes regenerados.

\section{REPARACIÓN DE LESIONES MEDULARES EXPERIMENTALES Movimiento y locomoción}

La contracción muscular y su consecuencia, el movimiento, subyace en todas las funciones de relación del ser humano. La acción coordinada de diferentes músculos hace posible hablar, escribir, caminar o utilizar herramientas. Muchas de las funciones viscerales también son posibles gracias a la contracción o relajación de fibras musculares. Los movimientos se clasifican en reflejos, rítmicos o automáticos y voluntarios [190], de acuerdo con el sistema neural que los induce.

Los movimientos reflejos son la forma más elemental de comportamiento motor. En ellos, una señal sensorial dispara la actividad de las neuronas motoras, y en consecuencia la de las fibras musculares, permitiendo actos que, aunque estereotipados, son útiles para la supervivencia. Un ejemplo simple es el reflejo de estiramiento de la rodilla, integrado en la médula espinal. Sobre los circuitos neurales sensitivomotores generadores de los movimientos reflejos, se han implementado numerosos sistemas de control que otorgan al organismo un mayor repertorio comportamental y le facilitan respuestas apropiadas a un medio complejo.

Los movimientos voluntarios son inducidos por señales neurales procedentes de sistemas de integración y control, como la corteza cerebral y los ganglios basales. La información sensorial desempeña también un papel crucial en su producción y se utilizan las mismas motoneuronas y fibras musculares (vía final común de Sherrington [191]) con una cinemática similar. Por ejemplo, la extensión voluntaria de la rodilla es similar a la mediada por el reflejo de estiramiento, pero la pauta neural que origina la actividad de las unidades motoras en los dos casos es muy diferente.

Entre los movimientos reflejos y los voluntarios se encuentra otra serie de actos, denominados movimientos rítmicos o automáticos, representados bastante bien por la locomoción. Son movimientos estereotipados, cuya ejecución -iniciación y velocidad- puede ser controlada por señales provenientes del encéfalo o de los sistemas sensoriales. Durante la locomoción, la extensión de la rodilla no ocurre, ni de forma refleja, ni voluntaria, sino como parte de una cadena cinemática automática, bajo el control de unidades motoras activadas rítmicamente por pautas procedentes de redes de interneuronas espinales: el llamado generador central de pauta (CPG, del inglés Central Pattern Generator) [192-194]. Estas redes reciben simultáneamente señales de sistemas sensoriales y del cerebelo, del tronco encefálico y de la corteza cerebral, las últimas bajo influencia de los ganglios basales.

\section{Evaluación de la locomoción: importancia de la metodología}

Los sistemas de control mencionados anteriormente permiten a cada organismo conferir un significado comportamental a sus movimientos automáticos. La locomoción con significado com- portamental [195] requiere el automatismo espinal de las pautas neurales que generan las sinergias de flexión y extensión de las extremidades. Pero, además, necesita:

- Señales de iniciación y detención, acopladas a las metas del organismo. Lainiciaciónnecesitauna señal paraadquirir la postura adecuada, y otra para iniciar la marcha propiamente dicha.

- Sistemas para el control del equilibrio, que generen la fuerza y las posturas adecuadas para mantener elevado el centro de gravedad y conseguir el desplazamiento.

- Sistemas que permitan la adaptación de la marcha al contexto en el cual se desenvuelve el organismo, es decir, la posibilidad de variar la velocidad, dirección, estilo y de corregir perturbaciones.

El movimiento normal es muy complejo y su perturbación por lesiones, por la reparación de éstas y por las respuestas adaptativas del individuo, aportan complejidades adicionales. Para conocer los mecanismos implicados en la reparación funcional de una lesión medular son esenciales métodos objetivos de evaluación cuantitativa de las funciones normales y reparadas. La cinemática analiza el movimiento en términos de desplazamiento, tiempo, velocidad y aceleración, utilizando las leyes de la mecánica clásica [196]. El análisis cinemático se complementa con la medición de las fuerzas asociadas al movimiento, la cinética. Puesto que las fuerzas que causan el desplazamiento son generadas por músculos bajo control neural, el registro de la actividad muscular y los estudios neurofisiológicos y neuroanatómicos son necesarios para conocer los procesos subyacentes. La cinemática, la cinética y la electromiografía (denominadas en conjunto técnicas fisiológicas) se han aplicado al estudio de la locomoción, principalmente en el gato y en el humano, $\mathrm{y}$ han proporcionado descripciones detalladas y conocimientos sólidos sobre su control [197]. La locomoción en la rata también se ha estudiado con estas técnicas [198-200], aunque casi todos los trabajos de reparación de lesiones medulares en roedores han utilizado escalas cualitativas arbitrarias [201-203]. Las estimaciones así realizadas son subjetivas, tienen baja resolución temporal y espacial, y no evalúan parámetros indispensables para entender la locomoción y qué se ha recuperado.

El contexto en que se realizan las evaluaciones influye decisivamente en la ejecución de la tarea por el animal, tanto al aplicar las escalas como las técnicas fisiológicas. Los estudios fisiológicos más esclarecedores sobre el control de la locomoción normal y patológica se han realizado con animales caminando sobre un tapiz rodante. En un experimento típico, un gato con sección completa de la médula espinal en niveles torácicos bajos y, por lo tanto, sin control voluntario de las extremidades posteriores y parte del tronco, es sujetado y elevado mientras el tapiz desplaza sus extremidades posteriores hacia atrás. Tras unos días de esta práctica, la información sensorial suministrada por la disminución de la carga y la movilización de las extremidades es suficiente para activar el CPG espinal, induciendo las sinergias flexoextensoras de la locomoción [204-206]. Si estos mismos animales se colocan sobre una superficie plana y estática, sin sostener su peso, los animales se desplazan utilizando sus extremidades anteriores, aunque eventualmente se desencadenan automatismos locomotores en las posteriores. Sin embargo, estos movimientos carecen de iniciación y detención voluntaria, de equilibrio, de coordinación con el resto del cuerpo y de adaptación al contexto, es decir, no tienen significado comportamental. Si este animal dejara de ser cuadrúpedo y ya no utilizara sus extremidades anteriores, sería incapaz de levantarse sobre sus extremidades posteriores y activar las cadenas cinemáticas para dar un paso manteniendo el equilibrio. Aunque estos movimientos no son locomoción, las propiedades de 
M. NIETO-SAMPEDRO, ET AL

Tabla II. Tratamientos que mejoran la función motora después de lesión experimental de la médula espinal.

\begin{tabular}{|c|c|c|c|c|c|}
\hline Lesión & Nivel & Animal & Tratamiento & Efecto informado y sistema de evaluación utilizado & Ref. \\
\hline STI & T8 & Rata adulta & Anticuerpo monoclonal IN-1 & Mejora reflejos, locomoción levemente, cinemática & [207] \\
\hline STI & T8 & Rata adulta & Anticuerpo monoclonal IN-1 & $\begin{array}{l}\text { Mejora la locomoción en escala BBB: } 12 / 21 \text { frente a } 10 / 21 \text {, } \\
\text { en viga estrecha: } 2 / 6 \text { frente a } 1 / 6 \text {, EMG en tapiz rodante }\end{array}$ & [208] \\
\hline STC-S & T8 & Rata adulta & Trasplante de nervios, aFGF & Mejora levemente la locomoción, cinemática & [209] \\
\hline STC-S & T9 & Rata adulta & Canales con células de Schwann & Mejora la locomoción, BBB: $8 / 21$ frente a 6/21 & [210] \\
\hline STI-S & T8 & Rata neonatal & Trasplante de segmento medular embrionario & Mejora la locomoción, reflejos, parámetros cinemáticos & [211] \\
\hline STC-S & T10 & Rata neonatal & Trasplante de segmento medular embrionario & Mejora reflejos y coordinación entre extremidades & [212] \\
\hline STC-S & $\mathrm{T7}$ & $\begin{array}{l}\text { Rata adulta } \\
\text { crónica }\end{array}$ & Segmento medular embrionario+FNT & Mejora la locomoción, cinemática & [220] \\
\hline STC-S & T8 & Rata adulta & Infusión de BDNF & Mejora la locomoción, BBB: 6/21 frente a 2/21 & [213] \\
\hline SUFL & C3 & Rata adulta & Fb-BDNF & Aumenta la frecuencia de uso de la extremidad anterior & [214] \\
\hline LETCE & C1 & Rata adulta & Trasplante de glía envolvente & Mejora el alcance con la extremidad anterior & [14] \\
\hline STC & T8 & Rata adulta & Trasplante de glía envolvente & Aumenta movimientos de flexoextensión al trepar & [15] \\
\hline STC-S & T10 & Rata adulta & Trasplante de mucosa olfatoria & Mejora la locomoción: BBB: 4/21 frente a 1/21 & [175] \\
\hline C-LI & T9 & Rata adulta & NeuroGel & Mejora la locomoción: BBB pre 4/21, post 5/21 & [215] \\
\hline LCD & T7 & Rata adulta & Fb-NT3 & Menos errores en la locomoción sobre una rejilla & [216] \\
\hline STC & T9 & Rata adulta & Trasplante de macrófagos activados & Mejora la locomoción, BBB: 7/21 frente a 1/21 & [217] \\
\hline C-LI & T10 & Rata adulta & Trasplante de células madre & Mejora la locomoción, BBB: 10/21 frente a 8/21 & [218] \\
\hline C & $\mathrm{T} 10$ & Ratón adulto & Polisacárido CM101 & Mejora la locomoción en campo abierto & [219] \\
\hline STC-S & T13 & Gato adulto & Agonistas noradrenérgicos & Mejoran la locomoción sobre un tapiz rodante, cinemática & [221] \\
\hline STC-S & T13 & Gato adulto & Agonistas serotoninérgicos & Mejoran la locomoción sobre un tapiz rodante, cinemática & [222] \\
\hline
\end{tabular}

STI: sección transversal incompleta; STI-S: sección transversal incompleta, retirando tejido; STC: sección transversal completa, sin retirar tejido; STC-S: sección transversal completa, retirando un segmento medular; SUFL: sección unilateral del funículo lateral; LETCE: lesión electrolítica del tracto corticoespinal; C-LI: contusión con lesión incompleta; LCD: lesión de las columnas dorsales; C: compresión; C-LI: compresión con lesión incompleta. Fb-: fibroblastos secretores de FNT (factores neurotróficos).

la médula espinal que los originan tienen algún potencial para desarrollar estrategias de utilidad para los pacientes.

Finalmente, ¿se ha logrado reparar la médula espinal lo suficiente para obtener locomoción con significado comportamental en animales de experimentación? Desafortunadamente, la respuesta es no. Los estudios experimentales de reparación de lesiones medulares más recientes se han resumido en la tabla II [207-222]. En estos estudios tres aspectos merecen especial consideración para analizar las relaciones entre reparación anatómica y recuperación funcional: a) la mayoría de las lesiones se realizan en niveles torácicos; b) la escala BBB y las puntuaciones por cumplimiento de tareas son la forma más utilizada de evaluar la función en roedores; c) las ganancias funcionales informadas en todos los casos son pequeñas y poco claras. Las deficiencias motoras pueden deberse a la muerte de neuronas en el segmento lesionado, o a la interrupción de tractos axonales. Los trastornos locomotores asociados a las lesiones torácicas son causados por el daño axonal, ya que la pérdida de neuronas de estos segmentos es silente con respecto a la locomoción [223]. Este hecho sugiere que los efectos locomotores asociados a intervenciones protectoras en los segmentos torácicos [219] no son debidos a la disminución de la muerte neuronal. En ese estudio la aparición de flexoextensión en las ex- tremidades dos días después de la lesión indicaría un efecto protector axonal y no prorregenerativo como sugieren los autores; en cualquier caso, el estudio no contiene evidencias anatómicas ni de protección ni de regeneración. Otra razón por la cual la localización de las lesiones en la región torácica es un factor determinante de los resultados funcionales es que los cuadrúpedos son capaces de desplazarse con las extremidades anteriores. El arrastre y la disminución de la carga en la parte caudal del cuerpo generan señales sensoriales cutáneas y propioceptivas, que ocasionalmente desencadenan automatismos locomotores en las extremidades posteriores en ausencia de regeneración axonal. La eficacia de dichas señales se puede aumentar directamente con varios tratamientos (p. ej., BDNF en ratas [213], agonistas serotoninérgicos y noradrenérgicos en gatos [221,222], o indirectamente facilitando el control de los músculos axiales a través de los segmentos sanos rostrales a la lesión [224,225]). Una situación similar parece presentarse al trepar. Las ratas con lesión medular completa aún pueden realizar esta tarea levantando su peso con las extremidades anteriores. Esta condición es particularmente propicia para desencadenar automatismos en las extremidades posteriores, que no soportan carga y se rozan con la superficie generando señales propioceptivas y cutáneas. Los efectos funcionales observados en estudios que han uti- 
lizado esta forma de evaluación, como los de Ramón-Cueto et al [15], podrían deberse a la facilitación sensorial [225]. Los animales de ese estudio no mostraban evidencia de recuperación funcional cuando se les colocaba sobre una superficie plana, lo cual indica carencia de control de la locomoción por mecanismos supraespinales. Tanto en el de Ramón-Cueto et al [15] como en otros trabajos, la confusión podría resolverse utilizando técnicas cinemáticas y cinéticas, correlacionando el impulso con el apoyo y la generación de fuerza por las extremidades posteriores.

Las intervenciones que producen ganancias funcionales evaluadas mediante la escala BBB para la locomoción en campo abierto [202] deben admitirse con reservas. En general, el promedio de ganancia funcional es bajo, aproximadamente 3 puntos de un total de 21 (Tabla II). En algunos casos, animales con lesión medular completa presentan mejoría en la parte baja de la escala, atribuida a la regeneración axonal $[175,217]$. Sin embargo, otros autores han asignado esas mismas puntuaciones a animales con lesiones completas, en ausencia de regeneración axonal [210,213]. Por otra parte, la escala suministra sólo una impresión subjetiva de la capacidad de soporte de carga con las extremidades posteriores y no toma en cuenta los parámetros que describen el ciclo de marcha y determinan la coordinación, como la duración de los tiempos de apoyo y equilibrio, el área de sustentación o la velocidad [197].

Sólo dos estudios han utilizado pruebas fisiológicas para medir la recuperación funcional. Merkler et al [208] han mostrado que ratas adultas con lesiones medulares incompletas $-\mathrm{y}$ por consiguiente, con capacidad locomotora residual- mejoraron ciertos parámetros cinemáticos y las características temporales del EMG durante la marcha sobre un tapiz rodante, después de la administración del anticuerpo monoclonal IN-1. Esta mejoría al parecer tuvo una contrapartida en la locomoción espontánea, como indicó la ganancia de dos puntos en la escala BBB. El anticuerpo IN-1 neutraliza al inhibidor de crecimiento neurítico Nogo-A, y promueve la regeneración de un pequeño porcentaje de axones del tracto corticospinal (alrededor del 5\%) y de algunas fibras serotoninérgicas y noradrenérgicas $[8,207]$. Aún no se dispone de estudios sobre la conectividad de los axones regenerados. Los efectos funcionales también podrían ser generados por la plasticidad sináptica inducida por el anticuerpo en otras regiones del SNC [226].

Por otra parte, Coumans et al [220] han utilizado trasplantes de segmentos medulares embrionarios conjuntamente con factores neurotróficos para promover la regeneración axonal en ratas adultas con sección completa de la médula espinal. Las intervenciones fueron mucho más eficaces cuando se realizaron dos y cuatro semanas después de la lesión. Axones de varios sistemas supraespinales crecieron en la zona distal de la médula, aunque en número escaso. La regeneración se asoció con una mayor presencia de pasos con soporte de peso al caminar sobre un tapiz rodante o al subir escaleras. Los autores no encontraron relación entre el número de neuronas con axones regenerados y el grado de recuperación funcional, lo que sugiere que la mejoría funcional requiere inervación específica.

\section{Recuperación funcional asociada a trasplantes de glía envolvente}

Actualmente existe una gran expectativa sobre lautilidad de trasplantes de GE como tratamiento para la lesión medular; sin embargo, se requieren muchas investigaciones adicionales para conocer su potencial real. Se ha informado que la GE induce la regeneración de algunos axones del tracto corticospinal dorsal, después de su lesión selectiva a nivel cervical por electrólisis [14] o por sección de las columnas dorsales [227]. Estos resultados han originado dudas por la presencia de lesiones incompletas, dejando intacta la porción ventral del tracto corticospinal en ambos y parte de la columna dorsal en el segundo. Aunque la regeneración se asoció con mejoras en la realización de una tarea de alcance dirigido con la extremidad anterior, otros investigadores han demostrado que esta capacidad puede recuperarse de forma espontánea [228]. Adicionalmente, la forma de evaluación del movimiento utilizada no permite discernir entre recuperación real y compensación a expensas de otros segmentos corporales [229]. Los trasplantes de GE en modelos de sección completa de la médula han favorecido la regeneración de algunos axones serotoninérgicos y sensoriales [15,66], cuyo impacto funcional ha sido discutido previamente en relación con la modulación de automatismos espinales. Los trasplantes de GE no ayudaron a los axones del fascículo longitudinal medial lesionado a crecer hacia sus dianas sinápticas del núcleo oculomotor externo [99]. Finalmente, los resultados obtenidos hasta la fecha en modelos de contusión medular a diferentes niveles no han sido positivos [230,231]. Takami et al [230] trasplantaron GE en contusiones torácicas una semana después de la lesión. No hubo regeneración de los sistemas supraespinales, incluidos los tractos corticospinal, vestibulospinal y reticulospinal. Dentro de los trasplantes se encontraron fibras propiospinales y sensoriales, aunque en menor cantidad en comparación con trasplantes de células de Schwann. No se evidenció ningún tipo de mejoría funcional, evaluada mediante la escala BBB, y en contusiones cervicales se obtuvieron resultados muy similares [231]. Los trasplantes de GE, realizados en forma inmediata o una semana después de la lesión, no promovieron la regeneración del tracto corticospinal. Sin embargo, fueron invadidos por fibras sensoriales y propiospinales, demostrando que las células conservan sus características promotoras de neuritogénesis para algunos tipos neuronales.

\section{CONCLUSIONES Y PERSPECTIVAS}

El sistema nervioso central posee células gliales con propiedades similares a las células de Schwann, capaces de promover la supervivencia neuronal y la neuritogénesis, de guiar el crecimiento axonal y de restituir a los astrocitos reactivos hipertróficos a su estado normal o de reposo. El trasplante de estas células en lesiones experimentales de la rama central de las raíces dorsales permite su reparación funcional. Ese tipo se lesión pueden ser reparado a todos los niveles medulares con la aproximación quirúrgica adecuada y con recuperación funcional parcial considerable. Estos modelos de avulsión de las raíces posteriores ofrecen una perspectiva optimista para lesiones hasta ahora intratables.

La superficie de los astrocitos reactivos contiene proteoglicanos que impiden la adhesión neuronal y la diferenciación y crecimiento de axones y dendritas. Estas moléculas son también repelentes para los conos de crecimiento y causan su retracción (colapso). Además, las células del SNC contienen glicolípidos capaces de inhibir la división de astroblastos normales y transformados.

Dos problemas fundamentales pendientes de solución son la muerte neuronal retrasada respecto al momento del trauma y la incapacidad intrínseca de los axones adultos para crecer como las fibras en desarrollo [232]. No hemos discutido aquí este serio problema, comunicado hace escasos meses y necesitado de confirmación independiente. No obstante, la pérdida de capacidad de crecimiento axonal con la edad ha sido una observación clínica y un problema experimental intuido y temido durante largo tiempo. La observación original se ha realizado en el sistema visual, el nervio óptico y la limitación del crecimiento depende de la interacción 
entre células ganglionares y amacrinas. Si esta limitación se confirmara en otros lugares del SNC, habría que estudiar la regulación de la expresión génica y la manera de obviar o resolver el problema. La muerte neuronal retrasada posiblemente pueda controlarse de manera sinergística con las terapias dirigidas a limitar la reactividad glial. La glía envolvente produce neurotrofinas y, trasplantada en lesiones, libera estos factores neurotróficos in situ. Ensayaremos esta terapia celular de neuroprotección en conjunción con tratamientos farmacológicos. Un efecto indirecto de la neuroprotección es la reducción de la reactividad glial. Pero la glía envolvente actúa también directamente sobre los astrocitos reactivos, y los normaliza. No sabemos cómo lo hace y el averiguarlo es otro de nuestros tópicos de trabajo. En todo caso, siempre se generarán algunos astrocitos reactivos, cuya superficie exhibe inhibidores de la regeneración axonal. La actividad inhibitoria será bloqueada con los anticuerpos monoclonales de ratón, inmunoglobulinas $\mathrm{G}$ específicas ya disponibles. Su fracción constante, específica de especie, será 'humanizada' mediante técnicas de biología molecular para evitar su rechazo por el sistema inmune del paciente. Estos tratamientos, utilizados simultáneamente, modificarán las zonas afectadas por la lesión directa e indirectamente, convirtiéndolas en un sustrato mejor de la supervivencia y crecimiento neuronales. La reparación funcional de las lesiones del SNC tendrá que tener en cuenta la respuesta espontánea de autorreparación del SNC y, por lo tanto, el momento poslesión en el que se debe operar. Puesto que la lesión cambia con el tiempo, el tratamiento requerirá probablemente intervenciones sucesivas en distintos momentos.
El momento presente es interesante y especial. El desarrollo de la biología molecular está suministrando una cantidad creciente de información que permite intuir problemas y soluciones, ambos posiblemente de realidad cuestionable. Por ejemplo, sabemos que existen proteínas que atraen o repelen fibras nerviosas concretas, lo que sugiere intervenciones futuras para restituir conexiones nerviosas con una especificidad y precisión comparables a las observadas durante el desarrollo. Pero aún no conocemos suficiente ni sobre esas proteínas ni sobre cómo hacerlas llegar a sus dianas en tejido lesionado. En definitiva, la reparación de lesiones medulares es un problema muy difícil de resolver, al que hemos tomado la medida solamente un poco mejor. Con una visión más realista de cuán difícil es, esperamos que la persistencia en lograrlo haga el resto.

La Unidad de Neurología Experimental del Hospital Nacional de Parapléjicos de Toledo es una unidad de investigación asociada al Instituto Cajal del CSIC, un servicio del hospital de nueva creación. Se están creando unidades similares en otros hospitales que reciben lesionados medulares, por ejemplo la Fundación Guttman en su nuevo centro de rehabilitación en Badalona (Barcelona). Como se puede inferir por la participación en esta revisión, los investigadores que trabajamos en la reparación de lesiones medulares en distintas comunidades y países colaboramos activamente. Nuestro trabajo durante el próximo quinquenio estará orientado primariamente a limitar la muerte neuronal retrasada, reducir la reactividad glial asociada al trauma y potenciar la regeneración axonal.

\section{BIBLIOGRAFÍA}

1. Nieto-Sampedro M, Cotman CW. Growth factor induction and temporal order in CNS repair. In Cotman CW, ed. Synaptic plasticity. New York: Guilford Press; 1985. p. 407-55

2. Balentine JD. Pathology of experimental spinal cord trauma. II. Ultrastructure of axons and myelin. Lab Invest 1978; 39: 254-66.

3. Ramón y Cajal S. Estudios sobre la degeneración y regeneración del sistema nervioso. Madrid: Imprenta hijos de Nicolás Moya; 1914.

4. Tello JF. La influencia del neurotropismo en la regeneración de los centros nerviosos. Trab Lab Invest Biol 1911; 9: 123-59.

5. David S, Aguayo A. Axonal elongation into PNS 'bridges' after CNS David S, Aguayo A. Axonal elongation into P
injury in adult rats. Science 1981;214: 931-3.

6. Nieto-Sampedro M, Lewis ER, Cotman CW, Manthorpe M, Skaper $\mathrm{SD}$, Barbin G, et al. Brain injury causes a time-dependent increase in neuronotrophic activity at the lesion site. Science 1982; 221: 860-1

7. Caroni P, Schwab M. Two membrane protein fractions from rat central myelin with inhibitory properties for neurite outgrowth and fibroblast spreading. J Cell Biol 1988; 106: 1281-8.

8. Schnell L, Schwab ME. Axonal regeneration in the rat spinal cord produced by an antibody against myelin associated neurite growth inhibiduced by an antibody against mye

9. Pindzola RR, Doller C, Silver J. Putative inhibitory extracellular matrix molecules at the dorsal root entry zone of the spinal cord during development and after root and sciatic nerve lesions. Dev Biol 1993; 156: 34-48.

0. Bovolenta P, Wandosell F, Nieto-Sampedro M. Neurite outgrowth over resting and reactive astrocytes. Res Neurol Neurosci 1991; 2: 221-8.

11. Cheng H, Cao Y, Olson L. Spinal cord repair in adult paraplegic rats: partial restoration of hind limb function. Science 1996; 273: 510-3.

12. Ramón-Cueto A, Nieto-Sampedro M. Regeneration into the spinal cord of transected dorsal root axons is promoted by ensheathing glia transof transected dorsal root axons is pron
plants. Exp Neurol 1994; 127: 232-44

13. Imaizumi T, Lankford KL, Waxman SG, Greer CA, Kocsis JD. Transplanted olfactory ensheathing cells remyelinate and enhance axonal conduction in the demyelinated dorsal columns of the rat spinal cord. $\mathrm{J}$ Neurosci 1998; 18: 6176-91

14. Li Y, Field PM, Raisman G. Repair of adult rat corticospinal tract by transplants of olfactory ensheathing cells. Science 1997; 277: 2000-2

15. Ramón-Cueto A, Cordero MI, Santos-Benito FF, Ávila J. Functional recovery of paraplegic rats and motor axon regeneration in their spinal cords by olfactory ensheathing glia. Neuron 2000; 25: 425-35.

16. Lipton P. Ischemic cell death in brain neurons. Physiol Rev 1999; 79: 1431-568.
17. Nieto-Sampedro M. Astrocyte mitogen inhibitor related to epidermal growth factor receptor. Science 1988; 240: 1784-6.

18. Abad-Rodríguez J, Vallejo-Cremades M, Nieto-Sampedro M. Control of glial number: purification from mammalian brain extracts of an inhibitor of astrocyte division. Glia 1998; 22: 160-71.

19. Abad-Rodríguez J, Bernabé M, Romero-Ramírez L, Vallejo-Cremades M, Fernández-Mayoralas A, Nieto-Sampedro M. Purification and structure of mez-Masoralas A, Nieto-Sampedro M.Punitication and structure of neurostatin, an inhibitor of astrocyte division of mammalian

20. Tator CH, Fehlings MG. Review of the secondary injury theory of acute spinal cord trauma with emphasis on vascular mechanisms. J Neurosurg 1991; 75: 15-26

1. Schwab ME, Bartholdi D. Degeneration and regeneration of axons in the lesioned spinal cord. Physiol Rev 1996; 76: 319-70.

22. Bovolenta P, Wandosell F, Nieto-Sampedro M. Characterization of a neurite outgrowth inhibitor expressed after CNS injury. Eur J Neurosci 1993; 5: 454-65.

23. Bovolenta P, Fernaud-Espinosa I, Méndez-Otero R, Nieto-Sampedro M. Neurite outgrowth inhibitor of gliotic brain tissue. Mode of action M. Neurite outgrowth inhibitor of gliotic brain tissue. Mode of action
and cellular localization, studied with specific monoclonal antibodies. and cellular localization, studied

24. Nieto-Sampedro M. Neurite outgrowth inhibitors in gliotic tissue. Adv Exp Med Biol 1999; 468: 207-24

25. Wandosell F, Bovolenta P, Nieto-Sampedro M. Differences between reactive astrocytes and cultured astrocytes treated with dibutiryl-cyclic AMP. J Neuropathol Exp Neurol 1993; 52: 205-15.

26. Oudenga M, Vargas CG, Weber AB, Kleitman N, Bunge MB. Longterm effects of methylprednisolone following transection of adult rat spinal cord. Eur J Neurosci 1999; 11: 2453-64.

27. Taoka Y, Okajima K, Uchiba M, Johno M. Methylprednisolone reduces spinal cord injury in rats without affecting tumor necrosis factor- $\alpha$ es spinal cord injury in rats without affecting
production. J Neurotrauma 2001; $18: 533-43$.

28. Bartholdi D, Schwab ME. Methylprednisolone inhibits early inflammatory processes but not ischemic cell death after experimental spinal cord lesion in the rat. Brain Res 1995; 672: 177-86.

29. Yan P, Xu J, Li Q, Chen S, Kim GM, Hsu CY, et al. Glucocorticoid receptor expression in the spinal cord after traumatic injury in adult rats. J Neurosci 1999; 19: 9355-63.

30. Scheinman RI, Gualberto A, Jewell CM, Cidlowski JA, Baldwin AS. Characterization of mechanisms involved in transrepression of NF-kB by activated glucocorticoid receptors. Mol Cell Biol 1995; 15: 943-53. 
31. Czeh G, Aitken P, Somjen GG. Membrane currents in CA1 pyramidal cells during spreading depression (SD) and SD-like hypoxic depolarization. Brain Res 1993; 632: 195-208.

32. Hansen AJ. Effects of anoxia on ion distribution in the brain. Physiol Rev 1985; 65: 101-48.

33. Somjen GG. Electrogenesis of sustained potentials. Prog Neurobiol 1973; 1: 199-237.

34. Herreras O, Somjen GG. Analysis of potentials shifts associated with recurrent spreading depression and prolonged unstable SD induced by microdialysis of elevated $\mathrm{K}^{+}$in hippocampus of anesthetized rats. Brain Res 1993; 610: 283-94.

35. Largo C, Ibarz JM, Herreras O. Effects of the gliotoxin fluorocitrate on spreading depression and glial membrane potential in rat brain in situ. $\mathrm{J}$ Neurophysiol 1997; 78: 295-307.

36. Hossman KA. Viability thresholds and the penumbra of focal ischemia. Ann Neurol 1994; 36: 557-65.

37. Herreras O, Somjen GG. Effects of prolonged elevation of potassium on hippocampus of anesthetized rats. Brain Res 1993; 617: 194-204

38. Largo C, Cuevas P, Somjen GG, Martín del Río R, Herreras O. The effect of depressing glial function on rat brain in situ on ion homeostasis, synaptic transmission and neuronal survival. J Neurosci 1996; 16: 1219-29.

39. Largo C, Cuevas P, Herreras O. Is glia disfunction the initial cause of neuronal death in ischemic penumbra? Neurol Res 1996; 18: 445-8.

40. Herreras O, Largo C, Ibarz JM, Somjen GG, Martín del Río R. Role of neuronal synchronizing mechanisms in the propagation of spreading neuronal synchronizing mechanisms in the propagation of spreading
depression in the in vivo hippocampus. J Neurosci 1994; 14: 7087-98.

41. Somjen GG. Mechanisms of spreading depression and hypoxic spread. Somjen GG. Mechanisms of spreading depression and hypoxic spread-
ing depression-like depolarization. Physiol Rev 2001; 81: 1065-96.

ing depression-like depolarization. Physiol Rev 2001; 81: 1065-96.
42. Kobayashi S, Harris VA, Welsh FA. Spreading depression induces tolerance of cortical neurons to ischemia in rat brain. J Cereb Blood Metab 1995; 15: 721-7.

43. Urban L, Neill KH, Crain BJ, Nadler JV, Somjen GG. Postischemic synaptic physiology in area CA1 of the gerbil hippocampus studied in vitro. J Neurosci 1989; 9: 3966-75.

44. Gudiño-Cabrera G, Nieto-Sampedro M. Ensheathing cells: large scale purification from adult rat olfactory bulb, freeze preservation and migration rification from adult rat olfactory bulb, freeze preservation and migration
of transplanted cells in adult brain. Rest Neurol Neurosci 1996; 10:25-34

of transplanted cells in adult brain. Rest Neurol Neurosci 1996; 10: 25-34.
45. Gudiño-Cabrera G, Nieto-Sampedro M. Schwann-like macroglia in adult rat brain. Glia 2000; 30: 49-63.

46. Reynolds R, Hardy R. Oligodendroglial progenitors labeled with the $\mathrm{O} 4$ antibody persist in the adult rat cerebral cortex in vivo. J Neurosci Res 1997; 47: 455-70.

47. de Virty F, Picart R, Jacque C, Tixier-Vidal A. Glial fibrillary acidic protein. A cellular marker of tanycytes in the mouse hypothalamus. Dev Neurosci 1981; 4: 457-60

48. Assouline JG, Pantazis NJ. Detection of a nerve growth factor receptor on fetal human Schwann cells in culture: absence of the receptor on fetal human astrocytes. Dev Brain Res 1989; 45: 1-14

49. Ramón-Cueto A, Nieto-Sampedro M. Glial cells from adult rat olfactory bulb: immunocytochemical properties of pure cultures of ensheathing cells. Neuroscience 1992; 47: 213-20.

50. Sommer I, Schachner M. Monoclonal antibodies (O1-O4) to oligodendrocyte cell surfaces: an immunocytological study in the central nervous system. Dev Biol 1981; 83: 311-22.

51. Barnett SC, Hutchins AM, Noble M. Purification of olfactory nerve ensheathing cells from the olfactory bulb. Dev Biol 1993; 155: 337-50

52. Barres BA A role for glia in LHRH release Curr Biol 1992; 2: 645-7.

52. Barres BA. A role for glia in LHRH release. Curr Biol 1992; 2: 645-7.
53. Hatton GI. Pituicytes, glia and control of terminal secretion. J Exp Biol 1988; 139: 67-79.

54. Theodosis DT, El Majdoubi M, Pierre K, Poulain DA. Factors governing activity-dependent structural plasticity of the hypothalamo neurohypophyseal system. Cell Mol Neurobiol 1998; 18: 285-98.

55. Martini R. Expression and functional roles of neural cell surface molecules and extracellular matrix components during development and regeneration of peripheral nerves. J Neurocytol 1994; 23: 1-28.

56. Monti-Graziadei GA, Graziadei PPC. Neurogenesis and neuron regeneration in the olfactory system of mammals. II. Regeneration and reeration in the olfactory system of mammals. II. Regeneration and re-
constitution of the olfactory sensory neurons after axotomy. J Neurocyconstitution of the olf
tol 1979; 8: 197-213.

tol 1979; 8: 197-213.
57. Kafitz KW, Greer CA. Olfactory ensheathing cells promote neurite extension from embryonic olfactory receptor cells in vitro. Glia 1999; 25: 99-110.

58. Sonigra RJ, Brighton PC, Jacoby J, Hall S, Wigley CB. Adult rat olfactory nerve ensheathing cells are effective promoters of adult central nervous system neurite outgrowth in coculture. Glia 1999; 25: 256-9.

59. Dellmann DH, Carithers J. Intrahypothalamically transected neurosecretory axons do not regenerate in the absence of glial cells. J Neural Transpl tory axons do not regen

60. Dellmann HD, Lue LF, Bellin SI. Neurosecretory axon regeneration into intrahypothalamic neural lobe allografts: neurophysin immunohistochemistry and fine structure. Exp Brain Res 1987; 67: 543-55.

61. Chauvet N, Parmentier ML, Alonso G. Transected axons of adult hypothalamic-neurohypophysial neurons regenerate along tanicytic processes. J Neurosci Res 1995; 41: 129-44.

62. Chauvet N, Privat A, Alonso G. Aged median eminence glial cell cultures promote survival and neurite outgrowth of cocultured neurons. Glia 1996; 18: 211-23

63. Chauvet N, Prieto M, Alonso G. Tanycytes present in the adult rat mediobasal hypothalamus support the regeneration of monoaminergic axons. Exp Neurol 1998; 151: 1-13.

64. Li Y, Field PM, Raisman G. Repair of adult rat corticospinal tract by transplants of olfactory ensheathing cells. Science 1997; 277: 2000-2

65. Pascual JI Gudiño-Cabrera G, Insausti R, Nieto-Sampedro M. Loss and restoration of rat urinary bladder function after lumbosacral rhizotomy and ensheathing glia transplantation. Soc Neurosci Abstr 1997; 23: 1720.

66. Ramón-Cueto A, Plant G, Ávila J, Bunge M. Long-distance axonal regeneration in the transected adult rat spinal cord is promoted by olfactory ensheating glia transplants. J Neurosci 1998; 18: 3803-15.

67. Imaizumi T, Lankford KL, Waxman SG, Greer CA, Kocsis JD. Transplanted olfactory ensheathing cells remyelinate and enhance axonal conduction in the demyelinated dorsal columns of the rat spinal cord. $\mathrm{J}$ Neurosci 1998; 18: 6176-91.

68. Navarro X, Valero A, Gudiño-Cabrera G, Flores J, Rodríguez FJ, Verdú $\mathrm{E}$, et al. Ensheathing glia transplants promote dorsal root regeneration and spinal reflex restitution after multiple lumbar rhizotomy. Ann Neurol 1999; 45: 207-15.

69. Pixley SK, Kobayashi Y, de Vellis J. A monoclonal antibody against vimentin: Characterization. Dev Brain Res 1984; 15: 185-99.

70. Wang C, Rougon G, Kiss JZ. Requirement of polysialic acid for the migration of the O-2A glial progenitor cell from neurohypophysial explants. J Neurosci 1994; 14: 4446-57.

71. Hu H, Tomasiewicz H, Magnusson T, Rutishauser U. The role of polysialic acid in migration of olfactory bulb interneuron precursors in the subventricular zone. Neuron 1996; 16: 735-43.

72. Anton ES, Weskamp G, Reichart LF, Matthew WD. Nerve growth factor and its low affinity receptor promote Schwann cell migration. Proc Natl Acad Sci U S A 1994; 91 : 2795-9.

73. Carter BD, Kaltschmidt C, Kaltschmidt B, Offenhauser N, Bohm-Matthaei R, Baeuerle PA, et al. Selective activation of NF-kappa B by nerve growth factor through the neurotrophin receptor p75. Science 1996; 272: 542-5.

74. Franceschini IA, Barnett SC. Low-affinity NG receptor and E-N-CAM expression define two types of olfactory nerve ensheathing cells that share a common lineage. Dev Biol 1996; 173: 327-43.

75. Bonfanti L Olive S, Poulain DA, Theodosis DT Mapping of the distribution of polysialylated neural cell adhesion molecule throughout the central nervous system of the adult rat: an immunohistochemical study. Neuroscience 1992; 49: 419-36.

76. Theodosis DT, Rougon G, Poulain DA. Retention of embryonic features by an adult neuronal system capable of plasticity: Polysialylated neural adhesion molecule in the hypothalamo-neurohypophyseal system. Proc Natl Acad Sci U S A 1991; 88: 5494-8.

77. Don Carlos LL, Monroy E, Morrell JI. Distribution of estrogen receptor-immunoreactive cells in the forebrain of the female guinea pig. J Comp Neurol 1991; 305: 591-612.

78. Tetel MJ, Blaustein JD. Immunocytochemical evidence for noradrenergic regulation of estrogen receptor concentrations in the guinea pig hypothalamus. Brain Res 1991; 565: 321-9.

79. Blaustein JD. Estrogen receptor immunoreactivity in rat brain: rapid effects of estradiol injection. Endocrinology 1993; 132: 1218-24.

80. Jung-Testas I, Schumacher M, Bugnard H, Baulieu EE. Stimulation of rat Schwann cell proliferation by estradiol: synergism between the estrogen and cAMP. Brain Res Dev Brain Res 1993; 72: 282-90.

81. Gudiño-Cabrera G, Nieto-Sampedro M. Estrogen receptor immunoreactivity in Schwann-like brain macroglia. J Neurobiol 1999; 40: 458-70.

82. Gudiño-Cabrera G, Nieto-Sampedro M. Schwann-like macroglia in adult rat brain. Glia 2000; 30: 49-63.

83. van Antwerp DJ, Martin SJ, Kafri T, Green DR, Verma IM. Suppression of TNF- $\alpha$-induced apoptosis by NF- $\mathrm{kB}$. Science 1996; 274: 787-9.

84. Carter BD, Lewin GR. Neurotrophins live or let die: does p75NTR decide? Neuron 1997; 18: 187-90.

85. Thompson CB. Apoptosis in the pathogenesis and treatment of disease. Science 1995; 267: 1456-62.

86. Arany Z, Sellers WR, Livingston DM, Eckner R. E1A-associated p300 and CREB-associated CBP belong to a conserved family of coactivators. Cell 1994; 77: 799-800.

87. Montminy M. Something new to hang your HAT on. Nature 1997; 387 : 654-5.

88. Jessen K, Mirsky R. Schwann cell precursors and their development. Glia 1991; 4: 185-94. 
89. Doucette JR. Astrocytes in the Olfactory Bulb. In Fedoroff S, Vernardakis A, eds. Astrocytes. Vol. 1. Orlando: Academic Press; 1986. p. 293-310.

90. Doucette R. Glial influences on axonal growth in the primary olfactory system. Glia 1990; 3: 433-49.

91. Cameron RS, Rakic P. Glial cell lineage in the cerebral cortex: a review and synthesis. Glia 1991; 4: 124-37.

92. Gard AL, Pfeiffer SE. Two proliferative stages of the oligodendrocyte lineage (A2B5+O4- and O4+GalC-) under different mitogenic control. Neuron 1990; 5: 615-25.

93. Reynolds R, Hardy R. Oligodendroglial progenitors labeled with the $\mathrm{O} 4$ antibody persist in the adult rat cerebral cortex in vivo. J Neurosci Res 1997; 47: 455-70.

94. Canoll PD, Musacchio JM, Hardy R, Reynolds R, Marchionni MA, Salzer JL. GGF/Neuregulin is a neuronal signal that promotes the glial proliferation and survival and inhibits the differentiation of oligodenproliferation and survival and inhibits the differ
drocyte progenitors. Neuron 1996; 17: 229-43.

95. Reichenbach A, Robinson SR. Ependymoglia and ependymoglia-like cells. In Kettenman H, Ransom BR, eds. Neuroglia. New York: Oxford University Press; 1995. p. 58-84.

96. Verdú, E, Navarro, X, Gudiño-Cabrera G, Rodríguez FJ, Ceballos D, Valero A, Nieto-Sampedro M. Olfactory bulb ensheathing cells enhance peripheral nerve regeneration. Neuroreport 1999; 10: 1097-101.

97. Franklin RJM, Barnett SC. Do olfactory glia have advantages over Schwann cells for CNS repair? J Neurosci Res 1997; 50: 665-72

98. Verdú E, García-Alías G, Forés J, Gudiño-Cabrera G, Nieto-Sampedro M, Navarro X. Effects of ensheathing cells transplanted into photochemically damaged spinal cord. Neuroreport 2001; 12: 2303-9.

99. Gudiño-Cabrera G, Pastor AM, de la Cruz R, Delgado-García JM, Nieto-Sampedro M. Limits to the capacity of transplants of olfactory glia to promote axonal regrowth in the CNS. Neuroreport 2000; 11: 467-71

100. Aldskogius H, Kozlova EN. Central neuron-glial and glial-glial interactions following axon injury. Prog Neurobiol 1998; 55: 1-26.

101. Fraher JP. The transitional zone and CNS regeneration [corrected and republished article originally printed in J Anat 1999; 194 (Pt 2): 161-82]. J Anat 2000; 196 (Pt 1): 137-58.

102. Fagan AM, Gage FH. Mechanisms of sprouting in the adult central nervous system: cellular responses in areas of terminal degeneration and reinnervation in the rat hippocampus. Neuroscience 1994; 58: 705-25.

103. Murray M, Wang SD, Goldberger ME, Levitt P. Modification of astrocytes in the spinal cord following dorsal root or peripheral nerve lesions. Exp Neurol 1990; 110: 248-57.

104. Bechmann I, Nitsch R. Astrocytes and microglial cells incorporate degenerating fibers following entorhinal lesion: a light, confocal, and electron microscopical study using a phagocytosis-dependent labeling techtron microscopical study using
nique. Glia 1997; 20: 145-54.

105. Kapadia SE, LaMotte CC. Deafferentation-induced alterations in the rat dorsal horn: I. Comparison of peripheral nerve injury vs. rhizotomy effects on presynaptic, postsynaptic, and glial processes. J Comp Neurol 1987; 266: 183-97.

106. Liuzzi FJ, Lasek RJ. Astrocytes block axonal regeneration in mammals by activating the physiological stop pathway. Science 1987; 237: 642-5.

107. Stensaas LJ, Partlow LM, Burgess PR, Horch KW. Inhibition of regeneration: the ultrastructure of reactive astrocytes and abortive axon terminals in the transition zone of the dorsal root. Prog Brain Res 1987; 71: 457-68.

108. Carlstedt T. Regenerating axons form nerve terminals at astrocytes. Brain Res 1985; 347: 188-91.

109. Sims TJ, Gilmore SA. Interactions between intraspinal Schwann cells and the cellular constituents normally occurring in the spinal cord: an ultrastructural study in the irradiated rat. Brain Res 1983; 276: 17-30.

110. Sims TJ, Gilmore SA. Regeneration of dorsal root axons into experimentally altered glial environments in the rat spinal cord. Exp Brain Res 1994; 99: 25-33.

111. Gilmore SA, Sims TJ. Glial-glial and glial-neuronal interfaces in radiation-induced, glia-depleted spinal cord. J Anat 1997; 190 (Pt 1): 5-21.

112. Lefrancois T, Fages C, Peschanski M, Tardy M. Neuritic outgrowth associated with astroglial phenotypic changes induced by antisense glial fibrillary acidic protein (GFAP) mRNA in injured neuron-astrocyte cocultures. J Neurosci 1997; 17: 4121-8.

113. Bovolenta P, Wandosell F, Nieto-Sampedro M. Central neurite outgrowth over glial scar tissue in vitro. In Kater SB, Letourneau PC, Macagno ER, eds. The Nerve Growth Cone. Raven Press; 1991. p. 477-88

114. Bovolenta P, Wandosell F, Nieto-Sampedro M. CNS glial scar tissue: a source of molecules which inhibit central neurite outgrowth. Prog Brain Res 1992; 94: 367-79.

115. Fernaud-Espinosa I, Nieto-Sampedro M, Bovolenta P. Differential effects of glycosaminoglycans on neurite outgrowth from hippocampal and thalamic neurones. J Cell Sci 1994; 107: 1437-48.

116. Fernaud-Espinosa I, Nieto-Sampedro M, Bovolenta P. A neurite out- growth-inhibitory proteoglycan expressed during development is similar to that isolated from adult brain after isomorphic injury. J Neurobiol 1998; 36: 16-29.

117. Fernaud-Espinosa I, Nieto-Sampedro M, Bovolenta P. Differential activation of microglia and astrocytes in aniso- and isomorphic gliotic tissue. Glia 1993; 8: 277-91.

118. Hatten ME, Liem RK, Shelanski ML, Mason CA. Astroglia in CNS injury. Glia 1991; 4: 233-43.

119. Zhang Y, Anderson PN, Campbell G, Mohajeri H, Schachner M, Lieberman AR. Tenascin-C expression by neurons and glial cells in the rat spinal cord: changes during postnatal development and after dorsal root or sciatic nerve injury. J Neurocytol 1995; 24: 585-601.

120. Bradbury EJ, Moon LDF, Popat RJ, King VR, Bennett GS, Patel PN, Fawcett JW, McMahon SB. Chondroitinase ABC promotes functional recovery after spinal cord injury. Nature 2002; 416: 636-40.

121. Chen MS, Huber AB, van der Haar M, Frank M, Schnell L, Spillman $\mathrm{A}$, et al. Nogo-A is a myelin-associated neurite outgrowth inhibitor and an antigen for monoclonal antibody IN-1. Nature 2000; 403: 434-9.

122. Domeniconi M, Cao Z, Spencer T, Sivasankaran R, Wang KC, Nikulina E, et al. Myelin-associated glycoprotein interacts with the Nogo66 receptor to inhibit neurite outgrowth. Neuron 2002; 35: 283-90.

123. Behar O, Golden JA, Mashimo H, Schoen FJ, Fishman MC. Semaphorin III is needed for normal patterning and growth of nerves, bones and heart. Nature 1996; 383: 525-8

124. Wolock B, Milesi H. Brachial plexus: applied anatomy and operative exposure. In Gelberman RH, ed. Operative nerve repair and reconstruction. JB Lippincott Co.; 1991. p. 1255.

125. Mackinnon SE, Dellon AL. Brachial plexus injuries. In Anonymous Surgery of the peripheral nerve. New York: Thieme Medical Publishers, Inc.; 1988. p. 423-54.

126. Carlstedt T. Nerve fibre regeneration across the peripheral-central transitional zone. J Anat 1997; 190: 51-6.

127. Golding J, Shewan D, Cohen J. Maturation of the mammalian dorsal root entry zone-from entry to no entry. Trends Neurosci 1997; 20: 303-8.

128. Nieto-Sampedro M, Ramón-Cueto A. Transplants of ensheathing cells facilitate sensory fiber ingrowth and regeneration into adult spinal cord. Eur J Physiol 1994; 427 (Suppl 1): R 51.

129. Muñetón VC, Taylor JS, Nieto-Sampedro M. Rizotomía múltiple del plexo braquial: tipos de axones regenerados en la medula espinal y su relación con la glia envolvente trasplantada. Rev Neurol 1999; 30: 284.

130. Pascual JI, Gudiño-Cabrera G, Insausti R, Nieto-Sampedro M. Spinal implants of olfactory ensheathing cells promote axon regeneration and bladder activity after bilateral lumbosacral dorsal rhizotomy in the adult rat. J Urol 2002; 167: 1522-6.

131. Kinder MV, Bastiaanssen EHC, Janknegt RA, Marani E. Neuronal circuitry of the lower urinary tract; central and peripheral neuronal control of the micturition cycle. Anat Embryol 1995; 192: 195-209.

132. Nadelhafth I, de Groat WC, Morgan C. Location and morphology of parasympathetic preganglionic neurons in the sacral spinal cord of the cat revealed by retrograde axonal transport of horseradish peroxidase. $\mathrm{J}$ Comp Neurol 1980; 193: 265-81.

133. Nadelhaft I, de Groat WC, Morgan C. The distribution and morphology of parasympathetic preganglionic neurons in the cat sacral spinal cord as revealed by horseradish peroxidase applied to the sacral ventral roots. J Comp Neurol 1986; 249: 48-56.

134. Kuru M. Nervous control of micturition. Physiol Rev 1965; 45:425-94.

135. Pascual JI, Insausti R, Gonzalo LM. Urinary bladder innervation in male rat: termination of primary afferents in the spinal cord as determined by transganglionic transport of WGA-HRP. J Urol 1993; 150: 500-4.

136. de Groat WC, Nadelhaft I, Milne RJ, Booth AM, Morgan C, Thor K. Organization of the sacral parasympathetic reflex pathways to the urinary bladder and large intestine. J Auton Nerv System 1981; 3: 135-60.

137. Hancock MB, Peveto CA. Preganglionic neurons in the sacral spinal cord of the rat: an HRP study. Neurosci Lett 1979; 11: 1-5.

138. Nadelhaft I, Booth A. The location and morphology of preganglionic neurons and the distribution of visceral afferents from the rat pelvic nerve: neurons and the distribution of visceral afferents from the rat pelvic ne

139. Pascual JI, Insausti R, Gonzalo LM. The pelvic innervation in the rat: different spinal origin and projections in Sprague-Dawley and Wistar rats. Brain Res 1989; 480: 397-402.

140. Nadelhaft I, Roppolo J, Morgan C, de Groat WC. Parasympathetic preganglionic neurons and visceral primary afferents in monkey sacral spinal cord revealed following application of horseradish peroxidase to pelvic nerve. J Comp Neurol 1983; 216: 36-52.

141. Petras JM, Cummings JF. Sympathetic and parasympathetic innervation of the urinary bladder and urethra. Brain Res 1978; 153: 363-9.

142. Tabatabai M, Booth AM, de Groat WC. Morphological and electrophysiological properties of pelvic ganglion cells in the rat. Brain Res 1986; 382: 61-70. 
143. Schröder HD. Organization of the motoneurons innervating the pelvic muscles of the male rat. J Comp Neurol 1980; 192: 567-87.

144. Tanagho EA, Schmidt RA, Gomes de Araujo C. Urinary striated sphincter: what is its nerve supply? Urology 1982; 20: 415-7.

145. Yamamoto T, Satomi H, Ise H, Takatama H, Takahashi K. Sacral spinal innervations of the rectal and vesical smooth muscles and the sphincteric striated muscles as demonstrated by the horseradish peroxidase method. Neurosci Lett 1978; 7: 41-7.

146. Nakagawa S. Onuf's nucleus of the sacral cord in a south American monkey (Saimiri): its location and bilateral cortical input from area 4. Brain Res 1980; 191: 337-44.

147. Roppolo JR, Nadelhaft I, de Groat WC. The organization of pudendal motoneurons and primary afferent projections in the spinal cord of the rhesus monkey revealed by horseradish peroxidase. J Comp Neurol 1985; 234: 475-88.

148. de Groat WC, Kawatani M, Hisamitsu T, Booth AM, Roppolo JR, Thor $\mathrm{K}$, et al. Neural control of micturition: the role of neuropeptides. J Auton Nerv Sys 1986; (Suppl): 369-87.

149. Pascual JI, Insausti R, Gonzalo LM. Pudendal nerve topography in the rat spinal cord projections studied with the axonal tracer wheat germ agglutinin conjugated-horseradish peroxidase. J Urol 1992; 147: 718-22.

150. Mallory B, Steers WD, de Groat WC. Electrophysiological study of micturition reflexes in rats. Am J Physiol 1989; 257: 410-21.

151. Rijkhoff NJ, Wijkstra H, van Kerrebroeck PE, Debruyne FM. Urinary bladder control by electrical stimulation: review of electrical stimulation techniques in spinal cord injury. Neurourol Urodyn 1997; 16: 39-53.

152. Gajewski JB, Awad SA, Heffernan LPH, Benstead TJ, Downie JW. Neurogenic bladder in lower motor neuron lesion: long-term assessment. Neurourol Urodyn 1992; 11: 509-17

153. McDonagh RP, Forster DMC, Thomas DG. Urinary continence in spinal injury patients following complete sacral posterior rhizotomy. Br J Urol 1990; 66: 618-22.

154. Trop CS, Bennett CJ. Autonomic dysreflexia and its urological implications: a review. J Urol 1991; 146: 1461-9.

155. Schäfer W. Urodynamics of micturition. Curr Opin Urol 1992; 2: 252-6.

156. Höfner K. Urodynamic evaluation of lower urinary tract dysfunction. Curr Opin Urol 1992; 2: 257-62

157. de Marco EF, Blaivas JG. Voiding disorders. Curr Opin Urol 1993; 3: 262-5.

158. Tanagho EA. Anatomy of the lower urinary tract and mechanical interpretation of storage and voiding. Curr Opin Urol 1992; 2: 245-7.

159. Steers WD, Ciambotti J, Etzel B, Erdman S, de Groat WC. Alterations in afferent pathways from the urinary bladder of the rat in response to partial urethral obstruction. J Comp Neurol 1991; 310: 401-10.

160. Steers WD, de Groat WC. Effect of bladder outlet obstruction on micturition reflex pathways in the rat. J Urol 1988; 140: 606.

161. Mersdorf A, Schmidt RA, Tanagho EA. Urodynamic evaluation and electrical and pharmacologic neurostimulation. The rat model. Urol Res 1993; 21: 199-209.

162. Igawa Y, Mattiasson A, Andersson KE. Micturition and premicturition contractions in unanesthetized rats with bladder outlet obstruction. J Urol 1994; 151: 244-9

163. Yablonsky F, Savasta M, Feuerstein C, Poirier M. Effects of transection of the spinal cord in the rat. Cystometric and autoradiographic studies. J Urol 1994; 152: 1315-22.

164. Sengupta JN, Gebhart GF. Mechanosensitive properties of pelvic nerve afferent fibers innervating the urinary bladder of the rat. J Neurophysiol 1994; 72: 2420.

165. Su X, Senguota SN, Gebhart GF. Effects of opioids on mechanosensitive pelvic nerve afferent fibers innervating the urinary bladder of the rat. J Neurophysiol 1997; 77: 1566

166. Martínez-Piñeiro L, Trigo-Rocha F, Hsu GL, Lue TF, Schmidt RA, Tanagho EA. Response of bladder, urethral and intracavernous pressure to ventral lumbosacral root stimulation in Sprague-Dawley and Wistar rats. J Urol 1992; 148: 925-9.

167. Tammela T, Lasanen L, Waris T. Effect of distension on adrenergic innervation of the rat urinary bladder. Urol Res 1990; 18: 345-8.

168. Lasanen LT, Tammela TLJ, Liesi P, Waris T, Polak JM. The effect of acute distension on vasoactive intestinal polypeptide (VIP), neuropeptide Y (NPY) and substance P (SP) immunoreactive nerves in the female rat urinary bladder. Urol Res 1992; 20: 259-63.

169. Flood HD, Downie JW, Awad SA. Urethral function after chronic cauda equina lesion in cats. II. The role of autonomically-innervated smooth and striated muscle in distal sphincter dysfunction. J Urol 1990; 144: 1029-35.

170. Buti M, Verdú E, Navarro X. Evaluación de un modelo experimental de reparación por tubulización en lesiones de nervios periféricos. Rev Neurol 1992; 106: 259-65.

171. Schalow G. Conduction velocities and nerve fibre diameters of touch, pain, urinary bladder and anal canal afferents and alpha and gamma- motoneurons in human dorsal sacral roots. Electromyogr Clin Neurophysiol 1991; 31: 265-96.

72. Schalow G. Impulse pattern, innervation density and two point discrimination of skin and mucosal afferents in humans. Considerations for a sensory reinnervation of urinary bladder and canal anal in spinal cord lesions. Electromyogr Clin Neurophysiol 1992; 32: 259-85.

173. Alm P, Ekstrom J. Outgrow of cholinergic nerves in the rat urinary bladder either partially denervated or partially denervated and decentralized. Acta Physiol Scand 1981; 112: 179-83.

174. Itoh Y, Waldeck RF, Tessler A, Pinter MJ. Regenerated dorsal root fibers from functional synapses in embryonic spinal cord transplants. J Neurophysiol 1996; 76: 1236-45.

175. Lu J, Feron F, Ho SM, Mackay-Sim A, Waite PM. Transplantation of nasal olfactory tissue promotes partial recovery in paraplegic adult rats. Brain Res 2001; 889: 344-57.

176. Paíno CL, Fernández-Valle C, Bates ML, Bunge MB. Regrowth of axons in lesioned adult rat spinal cord: promotion by implants of cultured Schwann cells. J Neurocytol 1994; 23: 433-52.

177. Blakemore WF, Olby NJ, Franklin RJM. The use of transplanted glial cells to reconstruct glial environments in the CNS. Brain Pathol 1995; 5: 443-50.

178. Lachapelle F. Glial transplants: an in vivo analysis of extrinsic and intrinsic determinants of dysmyelination in genetic variants. Brain Pathol 1995; 5: 289-99.

179. Duncan ID, Milward EA. Glial cell transplants: experimental therapies of myelin diseases. Brain Pathol 1995; 5: 301-10

180. Meyerson BA, Ren B, Herregodts P, Linderoth B. Spinal cord stimulation in animal models of mononeuropathy: effects on the withdrawal response and the flexor reflex. Pain 1995; 61: 229-43.

181. Valero-Cabré A, Navarro X. Changes in spinal withdrawal reflexes after peripheral nerve injury and repair. J Neurophysiol 2002; 87: 1763-71.

182. Houle JD, Skinner RD, García-Rill E. Turner KL. Synaptic evoked potentials from regenerating dorsal root axons within fetal spinal cord tissue transplants. Exp Neurol 1996; 139: 278-90.

183. Itoh Y, Sugawara T, Kowada M, Tessler A. Time course of dorsal root axon regeneration into transplants of fetal spinal cord: I. A light microscopic study. J Comp Neurol 1992; 323: 198-208.

184. Taylor JS, Muñeton-Gómez VC, Eguía-Recuero R, Nieto-Sampedro M. Transplants of olfactory bulb ensheathing cells promote functional repair of multiple dorsal rhizotomy. Prog Brain Res 2001; 132: 641-54.

185. Belyantseva IA, Lewin GR. Stability and plasticity of primary afferent projections following nerve regeneration and central degeneration. Eur J Neurosci 1999; 11: 457-68.

186. Chung K, Lee WT, Carlton SM. The effects of dorsal rhizotomy and spinal cord isolation on calcitonin gene-related peptide-labeled terminals in the rat lumbar dorsal horn. Neurosci Lett 1988; 90: 27-32.

187. Piehl F, Arvidsson U, Johnson H, Dagerlind A, Hokfelt T, Terenius L, et al. Reappearance of calcitonin gene-related peptide-like immunoreactivity in the dorsal horn in the long-term dorsal root transected rat. Brain Res 1992; 585: 400-4

188. Traub RJ, Solodkin A, Ruda MA. Calcitonin gene-related peptide immunoreactivity in the cat lumbosacral spinal cord and the effects of multiple dorsal rhizotomies. J Comp Neurol 1989; 287: 225-37.

189. Hunt SP, Pini A, Evan G. Induction of c-fos-like protein in spinal cord neurons following sensory stimulation. Nature 1987; 328: 632-4.

190. Ghez C. The control of movement. In Kandel ER, Schwartz JH, Jessell T, eds. Principles of Neural Science. 3 ed. New York: Elsevier Science Publishing Co.; 1991. p. 533-47.

191. Sherrington CS. The integrative action of the nervous system. New Haven and London: Yale University Press; 1906.

192. Brown TG. The intrinsic factors in the act of progression in the mammal. Proc Roy Soc B 1911; 84: 308-19.

193. Jankwoska E, Jukes MGM, Lund S, Lundberg A. The effect of DOPA on the spinal cord. 5. reciprocal organization of pathways transmitting excitatory action to alpha motoneurons of flexors and extensors. Acta Physiol Scand 1967; 70: 369-88.

194. Grillner S, Zangger P. Locomotor movements generated by the deafferented spinal cord. Acta Physiol Scand 1974; 91: 38-39A.

195. Grillner S, Wallen P. Central pattern generators for locomotion, with special reference to vertebrates. Ann Rev Neurosci 1985; 8: 233-61.

196. Tipler P. Physics for scientists and engineers. Vol. I. 4 ed. New York: Freeman and Company; 1998

97. Orlovsky G, Deliagina T, Grillner S. Neuronal control of locomotion. New York: Oxford University Press; 1999

198. Cohen AH, Gans C. Muscle activity in rat locomotion: Movement analysis and electromyography of the flexors and extensors of the elbow. J Morph 1975; 146: 177-96

199. Broton J, Nikolic Z, Suys S, Calancie B. Kinematic analysis of limb position during quadrupedal locomotion in rats. J Neurotrauma 1996; 13: 409-16. 200. Hamers F, Lankhorst A, van Laar T, Veldhuis W, Gispen W. Automat- 
ed quantitative gait analysis during overground locomotion in the rat: its application to spinal cord contusion and transection injuries. J Neurotrauma $2001 ; 18: 187-201$.

201. Tarlov L, Klinger H. Spinal cord compression studies. II. Time limits for recovery after acute compression in dogs. Arch Neurol Psychiatry 1954; 71: 271-90

202. Basso M, Beatti M, Bresnahan J. A sensitive and reliable locomotor rating scale for open field testing in rats. J Neurotrauma 1995; 12: 1-21. 203. Muir GD, Webb A. Assessment of behavioural recovery following spinal cord injury in rats. Eur J Neurosci 2000; 12: 3079-86.

204. Grillner S, Rossignol S. On the initiation of the swing phase of locomotion in chronic spinal cats. Brain Res 1978; 146: 269-77.

205. Duysens J, Pearson K. Inhibition of flexor burst generation by loading ankle extensors muscles in walking rats. Brain Res 1980; 187: 321-32.

206. Lovely RG, Gregor RG, Roy RR, Edgerton VR. Effects of training on the recovery of full-weight-bearing stepping in the adult spinal cat. Exp Neurol 1986; 92: 421-35.

207. Bregman BS, Kunkel-Bagden E, Schnell L, Dai HN, Gao D, Schwab M. Recovery from spinal cord injury mediated by antibodies to neurite growth inhibitors. Nature 1995; 378: 498-501.

208. Merkler D, Metz G, Raineteau O, Dietz V, Schwab M, Fouad K. Locomotor recovery in spinal cord-injured rats treated with an antibody neutralizing the myelin-associated neurite growth inhibitor Nogo-A. J Neurosci 2001; 21: 3665-73.

209. Cheng H, Almström S, Giménez-Llort L, Chang R, Ögren S, Hoffer B, Olson L. Gait analysis of adult paraplegic rats after spinal cord repair. Exp Neurol 1997; 148: 544-57.

210. Guest JD, Rao A, Olson L, Bunge MB, Bunge RP. The ability of human Schwann cell grafts to promote regeneration in the transacted nud rat spinal cord. Exp Neurol 1997; 148: 502-22.

211. Kunkel-Bagdem E, Bregman BS. Spinal cord transplants enhance the recovery of locomotor function after spinal cord injury at birth. Exp Brain Res 1990; 81: 25-34

212. Iwashita Y, Kawaguchi S, Murata M. Restoration of function by replacement of spinal cord segments in the rat. Nature 1994; 367: 167-70.

213. Jakeman L, Wei P, Guan Z, Stokes BT. Brain-derived neurotrophic factor stimulates hindlimb stepping and sprouting of cholinergic fibers after spinal cord injury. Exp Neurol 1998; 154: 170-84.

214. Liu Y, Kim D, Himes T, Chow S, Schallert T, Murray M, et al. Transplants of fibroblasts genetically modified to express BDNF promote regeneration of adult rat rubrospinal axons and recovery of forelimb function. J Neurosci 1999; 19: 4370-87.

215. Woerly S, Doan V-P, Evans-Martin F, Paramore C, Peduzzi JD. Spinal cord reconstruction using Neuroge $\mathrm{l}^{\mathrm{TM}}$ implants and functional recovery after spinal cord injury. J Neurosci Res 2001; 66: 1187-97.

216. Grill R, Murai K, Blesch A, Gage FH, Tuszynki MH. Cellular delivery of neurotrophin-3 promotes corticospinal axonal growth and partial functional recovery after spinal cord injury. J Neurosci 1997; 17: 5560-72. 217. Rapalino O, Lazarov-Spiegler O, Agranov E, Velan G, Yoles E, Fraid-

\section{TRAUMA EN EL SISTEMA NERVIOSO}

\section{CENTRAL Y SU REPARACIÓN}

Resumen. Desarrollo. Las lesiones de cerebro y médula espinal están adquiriendo una creciente importancia social y económica. En los países desarrollados, el trauma accidental es la causa principal de la muerte de niños y adultos jóvenes. Solamente las enfermedades cardíacas y el cáncer superan a los accidentes como causa de mortalidad y, si examinamos los años de trabajo potencial perdidos, las lesiones del sistema nervioso central (SNC) superan a todos los demás problemas. La mayoría de las lesiones de cerebro y médula espinal ocurren en individuos menores de 45 años de edad y causan incapacidad crónica. El edema y otros fenómenos de fase aguda pueden tratarse eficazmente y las lesiones del SNC no son mortales, pero sí incurables. Conclusión. Las consecuencias finales de una lesión del SNC dependen del lugar dañado y la magnitud de la lesión: lo mejor que las terapias actuales pueden ofrecer es alivio de los síntomas y rehabilitación. Esta revisión examina el estado actual de la reparación funcional de lesiones experimentales traumáticas del sistema nervioso central. [REV NEUROL 2002; 35: 534-52]

Palabras clave. Cerebro. Función visceral. Lesión. Locomoción. Médula espinal. Movimiento voluntario. Muerte neuronal. Recuperación funcional. Recuperación sensorimotora. Reparación de lesiones. Trauma. akis M, et al. Implantation of stimulated homologous macrophages results in partial recovery of paraplegic rats. Nat Med 1998; 4: 814-21.

218. McDonald JW, Liu XZ, Qu Y, Liu S, Mickey SK, Turetsky D, et al. Transplanted embryonic stem cells survive, differentiate and promote recovery in injured rat spinal cord. Nat Med 1999; 5: 1410-2.

219. Wamil A, Wamil B, Hellerqvist C. CM101-mediated recovery of walking ability in adult mice paralyzed by spinal cord injury. Proc Natl Acad Sci U S A 1998; 95: 13188-93

220. Coumans J, Lin T, Dai HN, MacArthur L, McAtee M, Nash C, et al Axonal regeneration and functional recovery after spinal cord transection in rats by delayed treatment with transplants and neurotrophins. J Neurosci 2001; 21: 9334-44.

221. Chau C, Barbeau H, Rossignol S. Effects of intrathecal alpha1- and alpha2-noradrenergic agonists and norepinephrine on locomotion in chronic spinal cats. J Neurophysiol 1998: 79: 2941-63.

222. Barbeau $H$, Rossignol S. The effects of serotonergic drugs on the locomotor pattern and on cutaneous reflexes of the adult chronic spinal cat. Brain Res 1990; 514: 55-67.

223. Magnuson D, Trinder T, Zhang Y, Burke D, Morassutti D, Shields C. Comparing deficits following excitotoxic and contusion injuries in the thoracic and lumbar spinal cord of the adult rat. Exp Neurol 1999; 156: 191-204.

224. Giszter SF, Kargo WJ, Davies M, Shibayama M. Fetal transplants rescue axial muscle representations in M1 cortex of neonatally transected rats that develop weight support. J Neurophysiol 1998; 80:3021-30.

225. Pearson KG. Could enhanced reflex function contribute to improving locomotion after spinal cord repair? J Physiol 2001; 533: 75-81.

226. Raineteau O, Schwab M. Plasticity of motor systems after incomplete spinal cord injury. Nat Rev Neurosci 2001; 2: 263-73.

227. Nash H, Borke RC, Anders J. Ensheathing cells and methylprednisolone promote axonal regeneration and functional recovery in the lesioned adult rat spinal cord. J Neurosci 2002; 22: 7111-20.

228. Weidner N, Ner A, Salimi N, Tuszynski M. Spontaneous corticospinal axonal plasticity and functional recovery after adult central nervous system injury. Proc Natl Acad Sci U S A 2001; 98: 3513-8.

229. Muir GD, Whishaw IQ. Complete locomotor recovery following corticospinal tract lesions: measurement of ground reaction forces during overground locomotion in rats. Behav Brain Res 1999; 103: 45-53.

230. Takami T, Oudega M, Bates M, Wood P, Kleitman N, Bunge M. Schwann cell but not olfactory ensheathing glia transplants improve hindlimb locomotor performance in the moderately contused adult rat thoracic spinal cord. J Neurosci 2002; 22: 6670-81.

231. Collazos-Castro JE, Muñetón-Gómez VC, Gutiérrez-Dávila M, Soto VM, Nieto-Sampedro M. Cervical contusion in the spinal cord of the rat: chronic locomotor deficits and effect of ensheathing glia transplants. 3rd Deauville International Conference on Spinal Cord Injury. Normandy, France, 2002

232. Goldberg JL, Klassen MP, Hua Y. Barres BA. Amacrine-signaled loss of intrinsic axon growth ability by retinal ganglion cells. Science 2002; 296: $1860-4$.

\section{TRAUMATISMO DO SISTEMA NERVOSO CENTRAL E SUA REPARAÇÃO}

Resumo. Desenvolvimento. As lesões do cérebro e da medula espinal estão a adquirir uma importância social e económica crescente. Nos países desenvolvidos, o traumatismo acidental é a causa principal da morte de crianças e adultos jovens. Só as doenças cardíacas e o cancro ultrapassam os acidentes como causa de mortalidade e, se examinarmos os anos de trabalho potencial perdidos, as lesões do sistema nervoso central (SNC) superam todos os problemas. A maioria das lesões do cérebro e medula espinal ocorrem em indivíduos com menos de 45 anos de idade e causam incapacidade crónica. $O$ edema e outros fenómenos de fase aguda podem tratar-se eficazmente e as lesões do SNC, embora não sejam mortais, são incuráveis. Conclusão. As consequências finais de uma lesão do SNC depende do local lesionado e da magnitude da lesão; o que de melhor as terapias actuais podem oferecer é o alívio dos sintomas e a reabilitação. Esta revisão estuda o estado actual da reparação funcional de lesões experimentais traumáticas do sistema nervoso central. [REV NEUROL 2002; 35: 534-52]

Palavras chave. Cérebro. Função visceral. Lesão. Locomoção. Medula espinal. Movimento voluntário. Morte neuronal. Recuperação funcional. Recuperação sensitivo-motora. Reparação de lesões. Traumatismo. 